\section{Corneal deposits after the topical use of ofloxacin in two children with vernal keratoconjunctivitis}

Topical fluoroquinolones are broad spectrum, bactericidal agents with activity against both Gram positive and Gram negative corneal pathogens. Single drug administration with topical fluoroquinolones has been effectively used in treatment of bacterial ulcerative keratitis. The drugs are safe, but a white crystalline deposit, that in most cases spontaneously dissolved, has been reported ${ }^{1-4}$ with ciprofloxacin $0.3 \%$ and norfloxacin $0.3 \%$. Up to now this side effect has not been described with ofloxacin $0.3 \%$. We present two children with severe vernal conjunctivitis who developed corneal deposits after use of ofloxacin $0.3 \%$ eye drops.

\section{Material and methods \\ Patient 1}

A 6 year old boy with vernal keratoconjunctivitis (VKC) developed a painful right eye while on holiday. His ophthalmologist diagnosed a corneal ulcer and prescribed ofloxacin eye drops followed by ofloxacin ointment four times a day for 3 weeks, associated with pred nisolone drops. As the inflammation in the right eye persisted, the child was referred to our department. Slit lamp examination revealed mild VKC and a corneal ulcer with dense, white, sharply demarcated crystalline deposit (Fig 1). All topical treatment was discontinued, but since the deposit did not spontaneously disappear and inflammation persisted, corneal scraping was performed 7 days later to remove the deposit. The sample was analysed by low contrast microscopy.

\section{Patient 2}

A 4 year old boy was referred for severe bilateral VKC with a corneal erosion in the right eye. One month before referral the child had had a corneal erosion in the right eye caused by the rubbing of a giant papilla on his upper eyelid. After an initial good response to terramycin ointment with fluorometholone and emadine, an increase in symptoms was observed. A topical treatment with ofloxacin ointment and patching was initiated, but the inflammation persisted. On administration to our department we observed a corneal ulce associated with a white round crystalline deposit in the right eye. Ofloxacin treatment

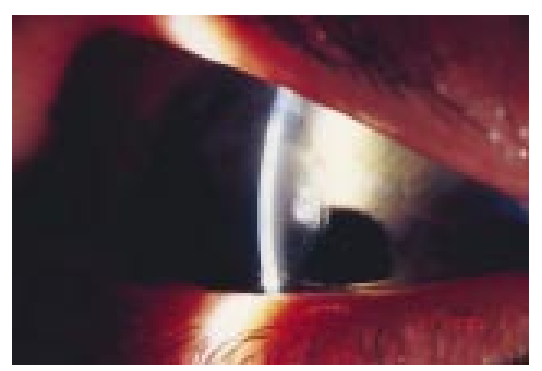

Figure 1 Slit lamp detail of vernal keratoconjunctivitis associated ulcer with a white sharply demarcated ofloxacin deposit. was discontinued, but the deposit did not dissolve and inflammation persisted. Twelve days after the discontinuation of the topical treatment a corneal scraping of the deposit was performed in combination with a subtarsal injection of corticosteroids in both eyes.

\section{Results}

The corneal scraping was analysed by microscopy. To that end, pefloxacin was added as internal standard and the minute tissue sample was extracted with an acid (formic acid, $\mathrm{pH}$ 3.0) mixture of water/acetonitrile (60/40). An aliquot was injected onto a $1 \mathrm{~mm} \times 15 \mathrm{~cm}$ Inertsil ODS $C_{18}$ column $(5 \mu \mathrm{m})$, eluted isocratically $(40 \mu \mathrm{l} / \mathrm{min})$ with $90 / 10$ water acetonitrile $\mathrm{pH}$ 3.0. Detection was performed using a Q-TOF mass spectrometer (Micromass, Manchester, UK) in the MS/MS mode. The retention time data and the full scan product ion spectrum (major diagnostic ions $\mathrm{m} / \mathrm{z}$ 362.1, 318.1, and 264.1) unequivocally disclosed that ofloxacin was present in the deposit. After removal of the deposit the ulcer epithelialised rapidly.

\section{Comment}

Topical ofloxacin $0.3 \%$ has been used in the treatment of patients with bacterial keratitis, in an animal model of keratitis ${ }^{5}$ and has been tested in an in vitro tear model. ${ }^{67}$ So far no reports of corneal deposits have been made. There is only one case report in which deposits are described after the combined use of cyclosporin and ofloxacin ${ }^{8}$; however, the authors attributed the deposit to the use of cyclosporin, although they did not conduct an analysis on the corneal deposits

We report for the first time two children who demonstrate corneal deposits of ofloxacin adherent to a corneal erosion caused by VKC. Analysis of a corneal deposit proved the presence of ofloxacin while treatment had been discontinued for 7 days, indicative of ofloxacin depot formation by precipitation.

The exact factors contributing to the formation of the fluoroquinolone precipitate are unknown, but $\mathrm{pH}$ solubility profiles are of importance. Ofloxacin, like the other fluoroquinolones, exhibits $\mathrm{pH}$ dependent solubility. In the in vitro tear model ${ }^{7}$ tear drug concentration of ofloxacin remained below solubility at all $\mathrm{pH}$ values tested $(\mathrm{pH}$ 6.4-7.2).

One could argue that VKC associated ulcers occur in a different "microenvironment" compared to bacterial ulcers. Mast cell activation leads to the release of different mediators and inflammatory cells, such as histamine, serotonin, heparin, prostaglandins, protease, tryptase and eosinophils, all of which can contribute to a "microenvironment" potentially promoting ofloxacin precipitation in one way or the other. It would be interesting to find out whether there are significant changes, $\mathrm{pH}$ or other, in the tears of children with VKC

In conclusion, we can say that ofloxacin does not seem to form corneal deposits when used in the treatment of bacterial ulcers, contrary to ciprofloxacin or norfloxacin. However, clinicians should be aware that deposits can occur after the use of ofloxacin in VKC associated ulcers.

\section{Acknowledgements}

This work was supported in part by grant GOA99120501.99 (Bijzonder OnderzoeksFonds).
Ilse Claerhout is a research assistant of the Flemish Fund for Scientific Research (FWO-Vlaanderen), Belgium

I Claerhout, Ph Kestelyn, F Meire

Department of Ophthalmology, Ghent University Hospital, Belgium

J-P Remon

Laboratory of Pharmaceutical Technology

T Decaestecker, J Van Bocxlaer Laboratory of Medical Biochemistry and Clinical Analysis, Ghent University, Belgium

Correspondence to: Françoise Meire, Department of Ophthalmology Ghent University Hospital, De Pintelaan 185, 9000 Gent, Belgium; françoise.meire@rug.ac.be

Accepted for publication 31 July 2002

\section{References}

1 Pranja NV, George C, Selvaraj S, et al. Bacteriologic and clinical efficacy of ofloxacin $0.3 \%$ versus ciprofloxacin $0.3 \%$ ophthalmic solutions in the treatment of patients with culture-positive bacterial keratitis. Cornea 2001;20:175-8.

2 Konishi M, Yamada M, Mashima Y. Corneal ulcer associated with deposits of norfloxacin. Am J Ophthalmol 1998;125:258-60.

3 Castillo A, Benitez Del Castillo JM, Toledano $N$, et al. Deposits of topical norfloxacin in the treatment of bacterial keratitis. Cornea 1997; 16:420-3.

4 Eiferman RA, Snyder JP, Nordquist RE. Ciprofloxacin microprecipitates and macroprecipitates in the human cornea epithelium. J Cataract Refract Surg 2001;27:1701-2.

5 Rao SN, Fong Y, Kampmeier J, et al. The effectiveness of a topical antibiotic irrigating solution in a model of staphylococcal keratitis after lamellar keratectomy. Am J Ophthalmol 2000;130:20-4.

6 Essepian JP, Raipal R, O'Brien TP. Tandem confocal microscopic analysis of ciprofloxacin corneal deposits in vivo. Cornea $1995 ; 14: 402-7$

7 Firestone BA, Dickason MA, Tran T Solubility characteristics of three fluoroquinolone ophthalmic solutions in an vitro tear model. Int J Pharm 1998; 164:119-28.

8 Kachi S, Hirano K, Takesue $Y$ et al. Unusual corneal deposit after the topical use of cyclosporine as eyedrops. Am J Ophthalmol 2000;130:667-9.

\section{Chromosomal translocation in a} family with ocular anomalies: indications for karyotype analysis

Hereditary isolated congenital malformations such as congenital cataracts or anterior segment anomalies are usually considered to be the result of a single gene mutation. The identification of associated abnormalitiesdysmorphic features, a malformation in another organ system, or mental handicap, help to identify those who carry more severe genetic defects such as chromosome rearrangements. We describe a family where two otherwise healthy men, a father and son, had juvenile cataracts. They both had offspring with more severe ocular anomalies including anterior segment dysgenesis, as well as mental retardation and dysmorphic features. Recent karyotype analysis revealed a balanced 
translocation in both father and son and a derived unbalanced translocation in their more severely affected children. Analysis of the translocation breakpoints led to the identification of a new human disease gene, $M A F$ in lens and anterior segment development. Critically, for the family, the finding of the translocation provides an explanation for the severe ocular and other anomalies in the individuals with the unbalanced derivative karyotype. In addition, it allows the option of prenatal diagnosis for future offspring for individuals carrying the balanced translocation.

\section{Family report}

A man with juvenile onset cataracts, and a family history of this, sought genetic advice with his partner. This man (II.3, Fig 1) was the father of three children with ocular anomalies and developmental delay. He had juvenile onset, progressive cataracts which were removed at the age of 24 years. The cataracts were described as widespread dot opacities, with anterior and posterior sutural densities. General and other ocular examination was normal.

This couple's only living child, a daughter age 5 years (III.3, Fig 1), had been noted at birth to have opaque corneas, small lens remnants in each eye, and very flat anterior chambers with rims of abnormal iris tissue. Bilateral microphthalmia was present with axial lengths of $12 \mathrm{~mm}$. Fundal examination and an ERG were normal. Bilateral corneal grafts were attempted, but rejection occurred This child had significant developmental delay with learning and motor difficulties, saying approximately five single words and only just walking at the age of 5 years. She had microcephaly and dysmorphic features (Fig 2A and B).

Two previous siblings, now dead, had also had ocular and other anomalies. The elder of these (III.1, Fig 1) had unilateral cataract, global developmental delay, and similar facial features to III.3 (Fig 2C). She died age 6 years as a result of aspiration pneumonia. The other sibling (III.2, Fig 1) had cloudy corneas at birth. She died soon after birth as a result of laryngeal stenosis (Fig 2D).

Analysis of the family history revealed that the patient's father (I.1, Fig 1), had also had juvenile onset cataracts but was otherwise well. He had two other children with ocular anomalies and mental impairment. The elder daughter (III.1, Fig 1), had juvenile onset cataracts and died age 29 years because of cardiac arrhythmia. The second daughter (III.2, Fig 1), developed cataracts in early childhood and had bilateral dense cataracts at the age of 30 years. Both these individuals had limited speech and required assistance with personal care. These women have dysmorphic facial features similar to those seen in their developmentally delayed nieces.

Karyotype analyses were requested on surviving family members. These demonstrated that the two otherwise normal men (I.l and II.3), with juvenile onset cataracts, were carriers of the same balanced translocation 46,XY,t (5;16)(p15.3;q23.2) (Fig 1). Their two surviving offspring (II.2 and III.3) with more severe ocular anomalies, mental retardation, and dysmorphic facial features both had the same unbalanced derivative karyotypes, 46,XX, der(5),t(5;16)(p15.3;q23.2) (Fig 1) Tissue had been taken at necropsy for karyotype analysis on III.2 which had also shown additional material on chromosome 5 This would be consistent with the unbalanced karyotype seen in her sibling, but unfortu-

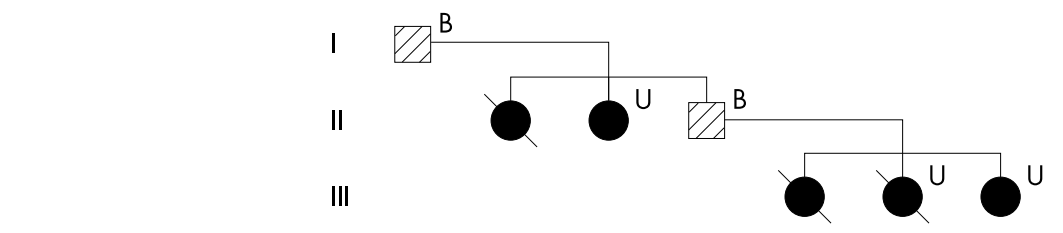

\begin{tabular}{|l|c|c|c|c|c|c|c|}
\hline & $\mathrm{I} .1$ & $\mathrm{II} .1$ & $\mathrm{II} .2$ & $\mathrm{II} .3$ & $\mathrm{III} .1$ & $\mathrm{III} .2$ & $\mathrm{III.3}$ \\
\hline Cataract & + & + & + & + & + & $\mathrm{NK}$ & + \\
\hline Anterior segment abnormal & - & - & - & - & - & + & + \\
\hline Myopia & - & - & + & - & - & - & - \\
\hline Microphthalmia & - & - & - & - & - & NK & + \\
\hline Mental retardation & - & + & + & - & + & NK & + \\
\hline Dysmorphic features & - & + & + & - & + & + & + \\
\hline Laryngeal stenosis & - & - & - & - & - & + & - \\
\hline Premature death & - & + & - & - & + & + & - \\
\hline
\end{tabular}

Cataract

Cataract and other ocular anomalies, mental retardation, dysmorphism

\section{$B=$ balanced translocation}

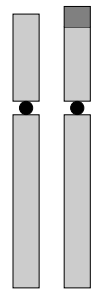

$5 \operatorname{der}(5)$

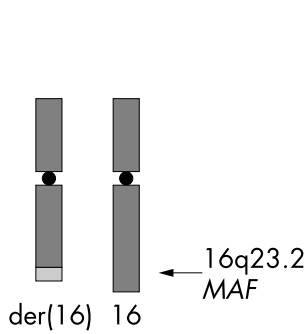

Figu

Pedigree and clinical features of translocation family. Individuals with the balanced translocation (B) have cataract alone, while those with the unbalanced derivative karyotype (U) have additional features including other ocular anomalies, mental retardation, dysmorphic features, and other malformations. In individuals with the balanced translocation (B)

$46, X Y, t(5 ; 16)(p 15.3 ; q 23.2)$, telomeric portions of $5 p$ and $16 q$ are translocated with no obvious loss of chromosomal material. Individuals with the unbalanced translocation (U), $46, X X, \operatorname{der}(5), t(5 ; 16)(\mathrm{p} 15.3 ; q 23.2)$, have inherited the derived chromosome 5 (der(5)) from their father as well as his normal chromosome 16 and their mother's normal 16, so they are trisomic for the telomeric portion of $16 \mathrm{q}$ containing MAF and monosomic for a small telomeric portion of $5 p$. NK = not known.

nately contact with the family about this at the time did not proceed. Karyotype analyses were not performed in II.1 or III.1 before their deaths and had not been performed in III.3 before the genetic referral.

\section{Comment}

The diagnosis of the chromosomal translocation has significant implications for management and options for individuals in this family. The indications for karyotype analysis are not specifically emphasised to ophthalmologists as this is generally not part of the ophthalmologist's role in patient care. Nevertheless, chromosomal anomalies are frequently reported in the ophthalmic literature and contributions to identification of several genes in human eye disease, including PAX6, FOXC1, PITX2, and MAF from this family, have been made through analysis of chromosome abnormalities..$^{1-4}$

In assessing the child with a congenital ocular anomaly, the presence of at least one other anomaly including another malformation or mental retardation, with or without dysmorphic features, is an indication for karyotype analysis. For the child, the finding of a chromosomal abnormality identifies the likely underlying cause, gives information regarding prognosis and directs management options. For the family, the origin of the chromosomal abnormality is critical in determin- ing the likelihood of recurrence in a future pregnancy.

The parents of a child with a chromosome abnormality should be offered karyotype analysis. If one of the parents is a carrier of a balanced form of the translocation, this carries a risk of recurrence of up to $20 \%$ or sometimes higher of having a malformed and mentally retarded child as a result of transmission of an unbalanced chromosomal complement. ${ }^{5}$ Couples where one partner is a balanced translocation carrier can be offered prenatal diagnosis in a future pregnancy. If a parent is a balanced translocation carrier, one of his or her parents may also be a carrier so that siblings and other more distant relatives may also carry the translocation with its attendant risks for a future pregnancy. If the parental karyotypes are normal, the chromosomal abnormality has probably arisen as a de novo event in the egg or sperm that went to make that child, and the likelihood of recurrence in a future pregnancy is low. Such risk analyses vary between families depending on family history and the particular chromosomal rearrangement: referral to a clinical genetics unit for assessment is recommended.

When a patient is seen with an ocular abnormality associated with mental retardation, dysmorphic features, or another malformation, a request or referral for karyotype analysis is indicated because of the significant 


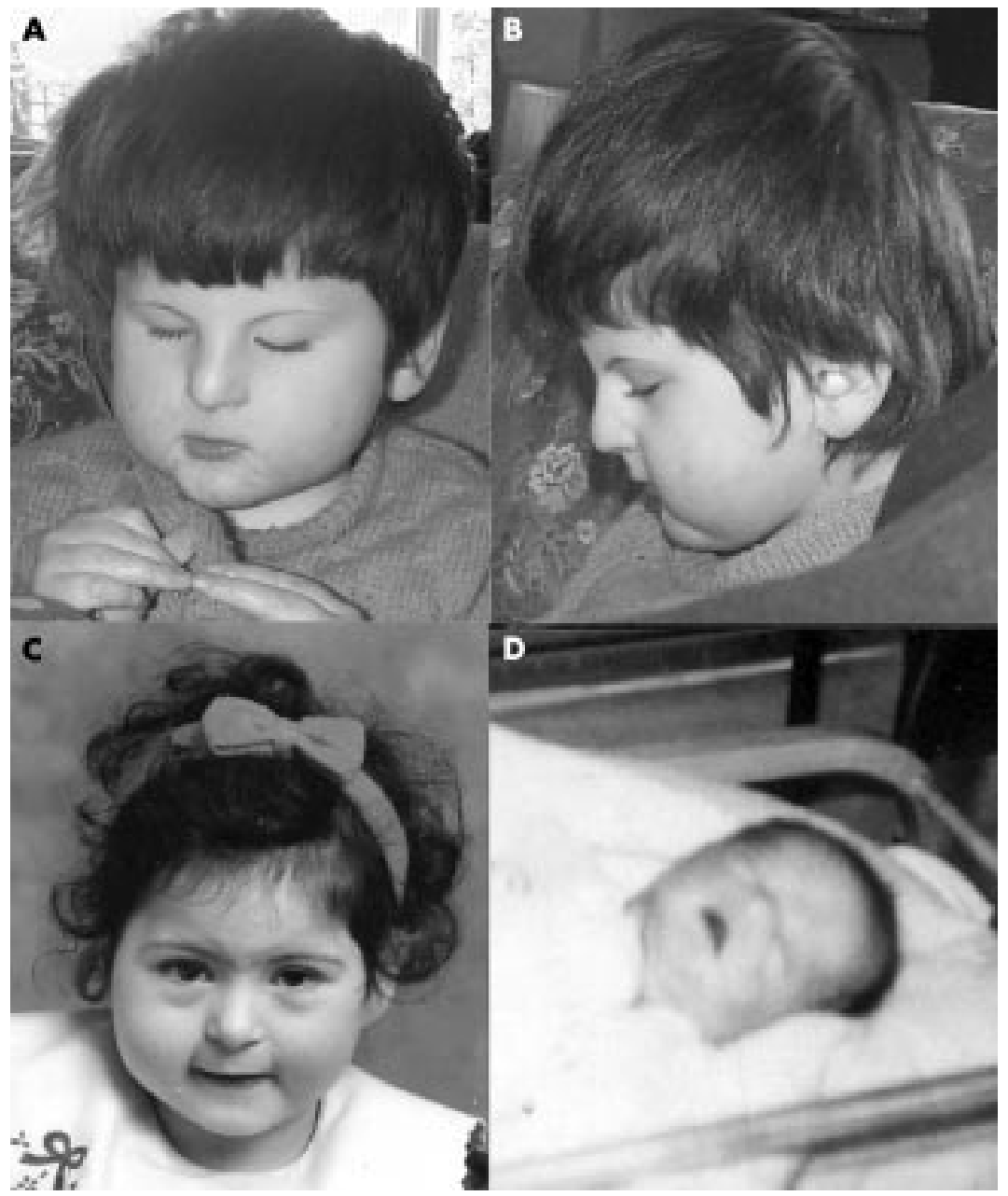

Figure 2 Facies of individuals with unbalanced translocation. (A and B) III.3, dysmorphic features include thin upper lip, short nose, microcephaly, brachycephaly, coarse hair, small hands with clinodactyly of second, fourth and fifth fingers. (C) III. 1, similar facial features to III.3. (D) III.2, infant dead as a result of laryngeal stenosis. Facial features include thin upper lip and featureless philtrum.

impact that the diagnosis of a chromosomal abnormality has for the individual and family. In this family the diagnosis of a familial chromosomal abnormality was made only recently. Before this five children were born over a period of 35 years with ocular abnormalities and associated features including mental retardation, dysmorphic features, and other non-ocular malformation, all caused by a chromosome abnormality derived from the balanced translocation in their parent.

\section{$\mathbf{R} \mathbf{V}$ Jamieson}

Academic Unit of Medical Genetics and Regional Genetic Service, St Mary's Hospital, Manchester, MI3 OJH, UK, and Department of Clinical Genetics, and Sydney University Department of Paediatric and Child Health, The Children's Hospital at Westmead, Sydney, NSW, 2145 Australia

L Gaunt, D Donnai, G C M Black Academic Unit of Medical Genetics and Regional Genetic Service, St Mary's Hospital, Manchester, MI3 OJH, UK

B Kerr, O Stecko Royal Manchester Children's Hospital, Manchester, UK

G C M Black

Academic Unit of Ophthalmology, Manchester Royal Eye Hospital, Manchester, Mi 3 9WH, UK
Correspondence to: R V Jamieson; robynj@chw.edu.au

Accepted for publication 4 September 2002

\section{References}

1 Jamieson RV, Perveen R, Kerr B, et al. Domain disruption and mutation of the bZIP transcription factor, MAF, associated with cataract, ocular anterior segment dysgenesis and coloboma. Hum Mol Genet 2002;11:33-42.

2 Fantes $\mathrm{J}$, Redeker B, Breen $M$, et al. Aniridia-associated cytogenetic rearrangements suggest that a position effect may cause the mutant phenotype. Hum Mol Genet 1995:4:415-22.

3 Nishimura DY, Swiderski RE, Alward WL, et al. The forkhead transcription factor gene FKHL7 is responsible for glaucoma phenotypes which map to $6 \mathrm{p} 25$. Nat Genet 1998; 19:140-7.

4 Flomen RH, Vatcheva R, Gorman PA, et al. Construction and analysis of a sequence-ready map in 4q25: Rieger syndrome can be caused by haploinsufficiency of RIEG, but also by chromosome breaks approximately $90 \mathrm{~kb}$ upstream of this gene. Genomics 1998;47:409-13.

5 Gardner RJM, Sutherland GR. Chromosome abnormalities and genetic counselling. Oxford: Oxford University Press, 1996.
Topiramate induced myopic shift and angle closure glaucoma

Topiramate (Topamax; Ortho-McNeil Pharmaceutical, Raritan, NJ, USA) is an oral sulfamate medication used primarily for seizure treatment. We report two cases of topiramate induced uveal effusions. In one case, prompt discontinuation of topiramate prevented bilateral angle closure glaucoma. To our knowledge, case 1 is the first case in the ophthalmic literature describing myopic shift without glaucoma.

\section{Case 1}

A 42 year old woman presented with a complaint of 1 day of blurry vision. Her medical history was notable for hypertension and seizures. She had never worn glasses. Medications included hydrochlorthiazide, Depakote, and Flovent. Topamax was started 2.5 weeks before examination which revealed 20/200 in both eyes without correction $(20 / 20$ both eyes with $-4.00-0.75 \times 76$ right eye $-4.00-1.00 \times 90$ left eye). Pupils and pressures were normal. Anterior chambers were shallow, and gonioscopy revealed angles open to posterior trabecular meshwork in both eyes. Cup-disc ratios were 0.3 in both eyes. Ultrasound revealed uveal effusions (Fig $1 \mathrm{~A}$ and $2 \mathrm{~A}$ ). Topamax was stopped. By day 3, the uveal effusions had decreased (Fig $1 \mathrm{~B}$ and 2B). By 1 week, she was able to see 20/20 (plano in both eyes). Chambers were now open to ciliary body in both eyes.

\section{Case 2}

A 50 year old woman presented with a complaint of 3 days of blurry vision. Her medical history was notable for uterine cancer, hypertension, asthma, depression, and morbid obesity. Drugs included Prozac, Vioxx, Zestril, and Flovent. Topamax was started 2 weeks earlier for weight loss. She saw 20/30 in both eyes with her glasses $(+2.00$ right eye +2.50 left eye). Pressures were $60 \mathrm{~mm} \mathrm{Hg}$ in both eyes. Pupils were barely reactive without APD. Anterior chambers were shallow without angle structures on gonioscopy. Since her pressures only decreased to the 30 s despite
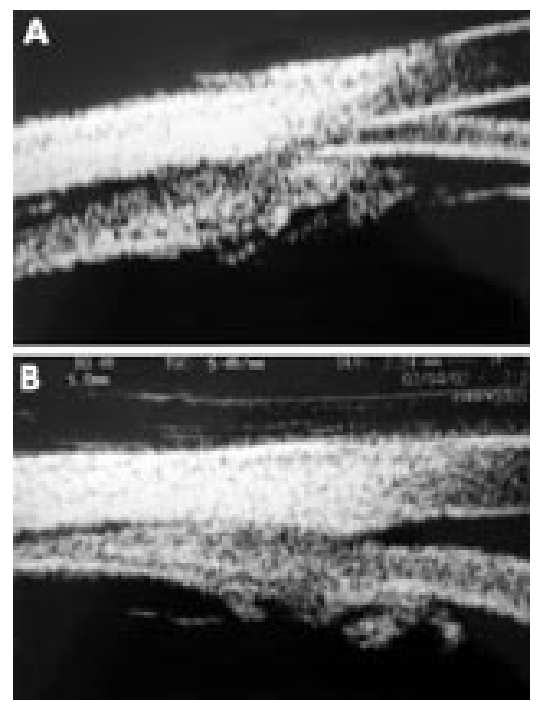

Figure 1 (A) Ultrasound biomicroscopy of case 1 (left eye) on the day of initial presentation. Ciliary body swelling and uveal effusions are present. (B) Case 1 (left eye) 3 days later. Uveal effusions are resolving and the angle is more open. 

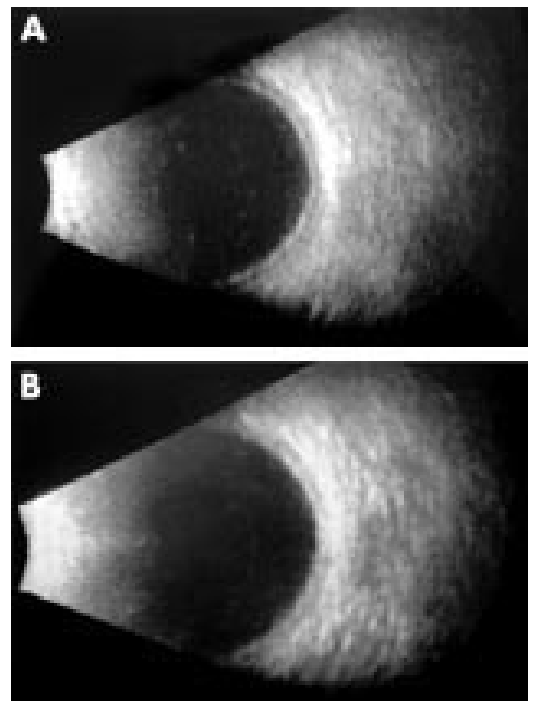

Figure 2 (A) B scan of case 1 (left eye) showing $360^{\circ}$ choroidal effusions. (B) Case 1 (left eye) 3 days later. Effusions are almost completely resolved.

maximal medications, laser iridotomy was performed in her right eye. She had stopped topiramate 1 day before presentation. On the second day, pressures were normal and B scan confirmed uveal effusions. By day 3, her vision was 20/20 in both eyes, and her pressures were normal on brimonidine $0.2 \%$ in both eyes. Gonioscopy revealed posterior trabecular meshwork right eye and no angle structures left eye (anterior chamber depths $2.69 \mathrm{~mm}$ right eye, $2.20 \mathrm{~mm}$ left eye). After 1.5 weeks, pressures were normal without medications. Angles were open to scleral spur in both eyes. Anterior chamber depths were $2.87 \mathrm{~mm}$ in both eyes. No uveal effusions were seen.

\section{Comment}

Drug induced myopia has been associated with sulfa drugs such as acetazolamide, sulfamethoxazole/trimethoprim, ${ }^{1}$ indapamide, promethazine, spironolactone, isosorbide dinitrate, and bromocriptine. ${ }^{2}$ Other drugs include tetracycline, ${ }^{12}$ corticosteroids, hydrochlorthiazide, penicillamine, quinine, metronidazole, isotretinoin, and aspirin. ${ }^{2}$ Recently, bilateral angle closure glaucoma with uveal effusions have been associated with topiramate. $^{34}$

Although the mechanism for topiramate induced myopia is unknown, it may partly be from topiramate's weak carbonic anhydrase inhibitor activity or a prostaglandin mediated effect. ${ }^{2}$ Since rechallenging at lower doses does not cause recurrence of myopia, ${ }^{5}$ allergic hypersensitivity is unlikely. Uveal effusions with ciliary body swelling cause forward rotation of the lens-iris diaphragm, causing myopia and angle closure glaucoma.

Including the three other cases in the ophthalmic literature which reported angle closure glaucoma, ${ }^{34}$ all were women between ages 34 and 53. The onset of high pressures varied from 1 day to 2.5 weeks. $^{34}$ Angle closure glaucoma has been noted in a 5 year old (Clark T, personal communication, 19 April 2002).

Although peripheral iridotomy may relieve some pupillary block (as suggested by case 2), most glaucoma cases resolve without miotics or iridotomy. Patients who develop blurred vision should promptly discontinue topiramate to prevent progression to angle closure glaucoma. Paediatric and developmentally delayed patients on topiramate should be closely monitored during the first 2 weeks of treatment.

\section{Acknowledgements}

We thank Karen Capaccioli, RDMS and Lois Hart, RDMS for their help in preparing the ultrasound images.

T C Chen

Harvard Medical School, Massachusetts Eye and Ear Infirmary, Glaucoma Service, 243 Charles Street, Boston, MA 02114 , USA

C W Chao

Harvard Medical School, Massachusetts Eye and Ear Infirmary, Department of Ophthalmology, 243 Charles Street, Boston, MA 02114 , USA

J A Sorkin

Childrens Hospital, Department of Ophthalmology, Microsurgical Consultants, 31 Centennial Drive, Peabody, MA 01960, UK

Correspondence to: Teresa C Chen, MD Massachusetts Eye and Ear Infirmary, Glaucoma Service, 243 Charles Street, Boston, MA 02114 , USA; teresa_chen @ meei.harvard.edu

Accepted for publication 8 September 2002

\section{References}

1 Bovino JA, Marcus DF. The mechanism of transient myopia induced by sulfonamide therapy. Am J Ophthalmol 1982;94:99-102.

2 Krieg PH, Schipper I. Drug-induced ciliary body oedema: a new theory. Eye 1996;10:121-6.

3 Sankar PS, Pasquale LR, Grosskreutz CL. Uveal effusion and secondary angle-closure glaucoma associated with topiramate use. Arch Ophthalmol 2001;119:1210-11.

4 Rhee DJ, Goldberg M, Parrish RK. Bilateral angle-closure glaucoma and ciliary body swelling from topiramate. Arch Ophthalmol 2001;119:1721-3.

5 Gubbay SS. The occurrence of drug-induced myopia as a transient side effect of topiramate [letter]. Epilepsia 1998;39:451.

\section{LASIK induced choroidal infarcts}

Laser in situ keratomileusis (LASIK) is now commonly used for correction of refractive error. Anterior segment complications relating to flap occurs occasionally. ${ }^{12}$ However, posterior segment complications are rare. ${ }^{3-10}$ Choroidal infarct following LASIK, to our knowledge, has never been reported. Here we report a case of bilateral choroidal infarct following a routine LASIK procedure.

\section{Case report}

A 23 years old woman underwent a LASIK excimer procedure to both eyes for correction of hypermetropia. Her preoperative refractive errors were right eye +5.00 and left eye +3.75 , improving vision to $6 / 6$ in the right eye and $6 / 5$ in the left eye. However, the axial length was not measured. She had no other ocular pathology. The anterior segments and the fundi were normal. She was generally healthy and her blood pressure was 120/76 $\mathrm{mm} \mathrm{Hg}$. Her routine blood tests and chest $x$ ray were within normal limits. She did not have any history of thromboembolic phenomenon, therefore a routine thrombophilia screening test was not performed.

An uncomplicated routine LASIK procedure was performed on 31 August 2001 in both eyes. The keratome used was Hansatome. Postoperatively, she complained of reduced and wavy vision, with floaters in both eyes. However, 2 months later (3 November 200l) she had been referred to one us $(\mathrm{RBJ})$. On examination now her vision was
6/18 with +1.0 D sph/+1.75D cyl@75 and 6/18, with -1.25 D sph/+1.50 D cyl@70in right and left eye respectively. There were normal LASIK scars and no corneal staining. The intraocular pressure (IOP) was $20 \mathrm{~mm} \mathrm{Hg}$ in both eyes. The anterior chambers were quiet and pupils reacted normally. The retinal examination showed multiple yellow-grey deep retinal lesions at posterior poles in both eyes. In each eye, there was at least one larger triangular shaped lesion measuring approximately $2 \times 3$ disc diameters in size temporal to the macula. There were several smaller satellite lesions around the macula, which were somewhat polygonal in shape. These lesions had sharp, well defined borders with a mild degree of retinal oedema. It should be noted that the lesions were almost symmetrical in each eye. The discs and blood vessels appeared normal. Fluorescein angiography showed normal transit of dye through the discs and blood vessels. The arteriovenous phase in each eye showed two typical triangular hyperfluorescent areas with apex pointing posteriorly. The smaller polygonal lesions showed punctate hyperfluorescence. The intensity of hyperfluorescence increased with the concentration of circulating dye during the transit and faded away towards the later phases of the angiography. The lesions were situated at a deeper level in comparison with the retinal blood vessels. The late phase in both eyes showed generalised staining of all lesions (Fig 1).
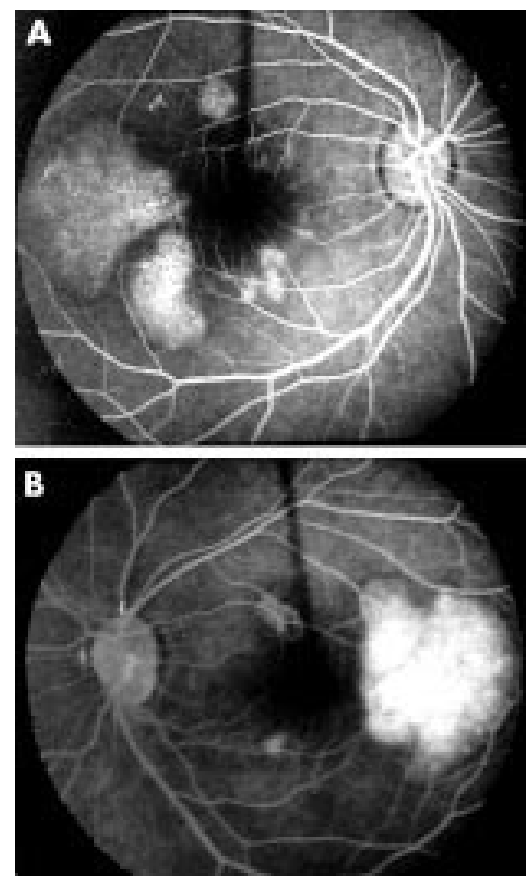

$\begin{array}{ll}\text { Figure } 1 & \text { (A) The arteriovenous phase of }\end{array}$ the fluorescein angiogram of the right eye shows two punctate hyperfluorescent triangular lesions with apex pointing towards the posterior pole on the temporal side of the macula. There are several smaller lesions above and below the macula. (B) The late venous phase of the fluorescein angiogram of the left eye done at the same session shows a large palquoid lesion on the temporal side of the macula with increased hyperfluorescence due to staining of the lesion. 
The patient was treated with $60 \mathrm{mg}$ of oral prednisolone in two divided dosage for 3 weeks which was then reduced to $20 \mathrm{mg}$ twice daily. She was reviewed fortnightly. She was also given flurbiprofen sodium $0.03 \%$ as local anti-inflammatory drops to both eyes three times daily for 4 weeks.

After 6 weeks the retinal oedema settled with visible fine peppery pigmentation over the lesions. Fluorescein angiography was repeated which showed increasing hyperfluorescence of all lesions during the transit with minimal staining towards the late phase.

On her final review her visual acuities were right eye 6/9 with +1.0 D sph/+0.50 D cyl @ $180^{\circ}$ and in left eye $6 / 6$ with $-1.0 \mathrm{D} \mathrm{sph} /-0.50$ D cyl @ $180^{\circ}$. The IOP was 18 mm Hg in each eye. The anterior chambers were quiet. The fundi showed well defined fine pigmented lesions with well defined borders. There were no fresh lesions or change in size of earlier lesions.

\section{Comment}

Flap related complications following LASIK surgery are well documented. ${ }^{12}$ Posterior segment complications such as bilateral macular haemorrhage, ${ }^{3}$ premacular subhyaloid haemorrhage, ${ }^{4}$ anterior ischaemic optic neuropathy (AION), ${ }^{5}$ retinal detachment, ${ }^{78}$ field defects, ${ }^{9}$ and macular hole ${ }^{10}$ have also been reported but to the best of our knowledge this is first case report of choroidal infarcts occurring after LASIK.

During the flap making stage of LASIK, application of suction may increase the IOP to as much as $60 \mathrm{~mm} \mathrm{Hg}$ or even more. This increase in IOP can result in poor perfusion leading to circulatory imbalance of the retina and the choroid. Alteration of perfusion pressure in susceptible individuals may precipitate clinical features of AION or choroidal infarct. In our case the increase in IOP might have reached much higher or be sustained for much longer period. This might have been the basis of infarction of choriocapillaris lobules. The smaller lobules coalesce to form larger lesions. Subsequent pigment changes seen were due to changes in the overlying retinal pigment epithelium.

Bilateral almost symmetrical lesions indicate that it could not have occurred exclusively as a result of raised IOP during LASIK. Therefore it is possible that this patient must have had other risk factors and she was susceptible to the effect of raised IOP. The refractive surgeons must be aware of the general physical status of a patient's health while considering keratorefractive surgery where a rise of IOP may be an associated factor.

R B Jain RBM Eye Institute, Delhi - 110 085, India A Chopdar

East Surrey Hospital, Redhill, Surrey RHI 5RH, UK Correspondence to: Dr R B Jain; drrbjain@bol.net.in

Accepted for publication 17 September 2002

\section{References}

1 Lyle WA, Jin GJC. Interface fluid associated with diffuse lamellar keratitis and epithelial ingrowth after laser in situ keratomileusis. J Cataract Refract Surg 1999; 25: 1009-12.

2 Portellinha W, Kuchenbuk M, Nakano K, et al. Interface fluid and diffuse corneal edema after laser in situ keratomileusis. I Refract Surg 2001;17:192-5

3 Luna JD, Reviglio VE, Juarez CP. Bilateral macular hemorrhage after laser in situ keratomileusis. Graefes Arch Clin Exp Ophthalmol 1999;237:611-13.
4 Mansour AM, Ojeimi GK. Premacular subhyaloid haemorrhage following laser in situ keratomileusis. J Refract Surg 2000; 26:371-2.

5 Cameron BD, Saffra NA, Strominger MB. Laser in situ keratomileusis induced optic neuropathy. Ophthalmology 2001; 108:660-5.

6 Lee AG, Kohnen T, Ebner R, et al. Optic neuropathy associated with laser in situ keratomileusis. J Cataract Refract Surg 2000;26:1581-4

7 Aras C, Ozdamar A, Karacorlu M, et al. Retinal detachment following laser in situ keratomileusis. Ophthalmic Surg Lasers 2000;31:121-5.

8 Arevalo JF, Ajar-Arevalo O. Retina detachment in myopic eyes after laser in situ keratomileusis. Am J Ophthalmol.2000;1 29:825-6

9 Bushley DM. Parmley VC. Paglen P. Visual field defects associated with laser in situ keratomileusis. Am J Ophthalmol 2000;1 29:668-71.

10 Chan CK, Lawrence FC. Macular hole after laser in situ keratomileusis and photorefractive keratectomy. Am J Ophthalmol

2001:131:666-7.

\section{A case of Boerhaave's syndrome associated with raised intraocular pressure}

We would like to report a fatal case of post-emetic oesophageal perforation (Boerhaave's syndrome). The condition was attributed to nausea and retching caused by raised intraocular pressure (IOP). We believe the case highlights the importance of early diagnosis and management of such rare cases.

\section{Case report}

An 81 year old man presented with a painful right eye. He felt nauseated and was retching. On examination visual acuity was $6 / 36$ pinhole $6 / 18$ right eye and $6 / 12$ pinhole $6 / 5$ left eye. The right eye was mildly inflamed and pseudophakic as a result of recent surgery. Right IOP was $58 \mathrm{~mm} \mathrm{Hg}$. The left eye showed no abnormality. Past ocular history included complicated right cataract surgery requiring pars plana vitrectomy and removal of lens fragment 6 weeks previously. Five weeks later he developed an inferior retinal detachment which was repaired by further vitrectomy, cryotherapy, encircling band, and gas tamponade $\left(\mathrm{SF}_{6} 20 \%\right)$. Following discharge he had been troubled by nausea and retching. Past medical history included moderate chronic obstructive pulmonary disease and treated essential hypertension. Medical examination was consistent with this. He was admitted and treated with intravenous Diamox and Maxolon, topical Alphagan and Trusopt. IOP was $33 \mathrm{~mm} \mathrm{Hg} 5$ hours later. Early the following morning he had one episode of blood stained vomitus following which he developed sudden retrosternal chest pain and dyspnoea. GTN spray and Gaviscon did not alleviate his symptoms. On examination he was very distressed and unable to lie flat. Cardiovascular and respiratory examination demonstrated no new pathology. His blood pressure, ECG, and oxygen saturation were normal. Abdominal examination revealed general tenderness and guarding in all quadrants. Abdominal and chest $x$ rays were unremarkable as was abdominal ultrasound. Urgent surgical and medical opinions were sought. At lunch time he developed further sudden severe dyspnoea and became confused. Blood gases revealed severe acidosis with reduced $\mathrm{PO}_{2}$ and $\mathrm{PCO}_{2}$. Physicians believed this was a mixed metabolic and respiratory acidosis induced by pulmonary thromboembolism. He was anticoagulated and transferred to the high dependency unit. Repeat chest $x$ ray at 20:00 showed a right sided pneumothorax. A chest drain was inserted. The pleuritic fluid sample contained bile, Gram positive cocci, and Gram negative rods. The patient, who by now was in septic shock, was commenced on broad spectrum intravenous antibiotics. Emergency laparotomy confirmed oesophageal perforation. After discussion with his family no further intervention was deemed justifiable. Our patient died a few hours later.

\section{Comment}

Boerhaave syndrome is transmural perforation of the oesophagus to be distinguished from Mallory-Weiss syndrome, nontransmural oesophageal tear also associated with vomiting. ${ }^{1}$ It is the result of a sudden rise in intraluminal oesophageal pressure produced during vomiting. Pain is the most consistent symptom, present in $70-90 \%$ of patients, and is usually related to the site of disruption (Table 1$){ }^{2}$ Chest $x$ ray suggests the diagnosis in $90 \%$ of patients, but immediately after disruption the chest film may be normal. ${ }^{3}$ Pneumomediastinum, surgical emphysema, mediastinal widening, or a mediastinal air-fluid level must prompt investigation to rule out oesophageal perforation. ${ }^{4}$ Survival depends upon early recognition and appropriate surgical intervention. The overall mortality rate is approximately $35 \%$. Surgical repair within 24 hours carries $70-75 \%$ chance of survival. This falls to $35-50 \%$ if surgery is delayed longer than 24 hours and to approximately $10 \%$ if delayed longer than 48 hours. ${ }^{5}$ Surgical intervention is the optimum management in most cases. ${ }^{6}$ This case highlights two very important points, firstly, the importance of adequate IOP control and associated nausea, secondly, although the above case is rare familiarity of the case and its inclusion in the differential diagnosis can be potentially life saving.

Table 1 Symptoms and signs of oesophageal perforation

\begin{tabular}{|c|c|}
\hline Symptoms & Signs \\
\hline Vomiting (common) & Tachycardia (common) \\
\hline Pain (common, may radiate to the back) & Fever (common) \\
\hline Chest hypersonarity or dullness (common) & Surgical emphysema (common) \\
\hline $\begin{array}{l}\text { Dysphagia (swallowing may precipitate } \\
\text { coughing) }\end{array}$ & $\begin{array}{l}\text { Haematemesis (uncommon) } \\
\text { Protosis (rare) }\end{array}$ \\
\hline Dyspnoea (common, due to pleuritic pain or & \\
\hline
\end{tabular}

pleural effusion) 
S Nabili, J R Murdoch North Glasgow University NHS Trust, Glasgow, UK

Correspondence to: Mr Shahriar Nabili, Ophthalmology Department, Gartnavel General Hospital, Great Western Road, Glasgow G12 OYN, UK; nabili@hotmail.com

Accepted for publication 18 September 2002

\section{References}

1 Datta CK, Brannon JV. Spontaneous rupture of esophagus (Boerhaave syndrome): a review of literature and a case presentation. W V Med J 1979:75:180-2.

2 White RK, Morris DM. Diagnosis and management of esophageal perforations. Am Surg 1992;58: 112-9.

3 Henderson JA, Peloquin AN. Boerhaave revisited: spontaneous esophageal perforation as a diagnostic masquerader. Am J Med 1989;86:559-67.

4 John BE, Zua MS. Boerhaave's syndrome-an elusive diagnosis. Tenn Med 1997:90:56-8.

5 Vyslouzil K. Rozh/ Chir 2000;79:521-3.

6 Bladergroen MR, Lowe JE, Postelthwait RW. Diagnosis and recommended management of esophageal perforation and rupture. Ann

Thorac Surg 1986;42:235-9.

\section{Severe bilateral necrotising retinitis caused by Toxoplasma gondii in a patient with systemic lupus erythematosus and diabetes mellitus}

Ocular toxoplasmosis may be remarkably atypical in situations of evident immunosuppression such as acquired immunodeficiency syndrome, malignancy, and use of chronic immunosuppressive drug therapy. ${ }^{1}$ Aggressive forms in immunocompetent hosts are very rare. $^{23}$ We present a case of severe, bilateral necrotising retinitis by Toxoplasma gondii initially misdiagnosed as an acute retinal necrosis (ARN) syndrome, in a patient with systemic lupus erythematosus (SLE) and diabetes mellitus type 2, who was taking medium dose prednisone.

\section{Case report}

A 47 year old woman reported a 3 month history of rapid visual loss in the right eye followed by a decrease in her left eye vision 2 months later. Twenty days before the onset of ocular symptoms the patient had a seizure. Her medical history showed a SLE, ${ }^{4}$ with an active lupus central nervous system disease controlled with prednisone $(0.5 \mathrm{mg} / \mathrm{kg} /$ day $)$, and type 2 diabetes mellitus. At her first visit to our service, visual acuity was hand movements in both eyes. Slit lamp examination showed $3+$ aqueous cells and flare, and $2+$ anterior vitreous cells in both eyes. The fundus showed a $2+$ vitreous haze and almost $360^{\circ}$ creamy white necrotising retinitis extending from the ora serrata to the posterior pole, including the macula in both eyes (Fig $1 \mathrm{~A}$ and $\mathrm{B})$. Thumbprint patches at the border between necrotic and scanty normal retina could be observed, and also diffuse vascular attenuation.

Cerebral spinal fluid analysis showed pleocytosis, hypergammaglobulinaemia, and negative serology, including VDRL. Complement level was normal, anti-double stranded DNA and anti-cardiolipin (ACL) antibodies were negative, and activated partial thromboplastin time (aPTT) was normal, not fulfilling the international consensus criteria to antiphospholipid syndrome. ${ }^{5}$ Serum antiToxoplasma and anti-herpes virus IgG were positive by enzyme immunoassays, while
anti-HIV-1 and HIV-2 was negative. Tests for specific IgM were all negative; serum FTA-Abs was positive; VDRL was negative. Complete blood count and platelets were normal. Chest $x$ ray was also normal.

A presumptive diagnosis of ARN was made in a patient with active systemic lupus disease. Intravenous aciclovir was introduced and prednisone therapy was maintained.

Owing to failure of the antiviral treatment and ocular disease progression, the patient underwent a chorioretinal biopsy of the right eye for a definite diagnosis, mainly to discharge a tumoral retinochoroidal infiltration. Two blocks of choroid and retina, and also a vitreous sample, were obtained. Polymerase chain reaction (PCR) was unexpectedly positive for $T$ gondii and negative for the herpesvi-
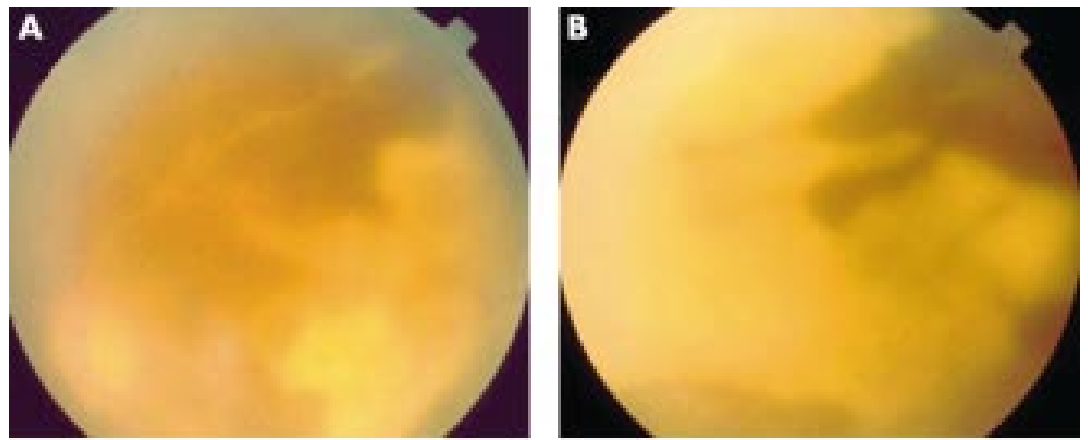

C

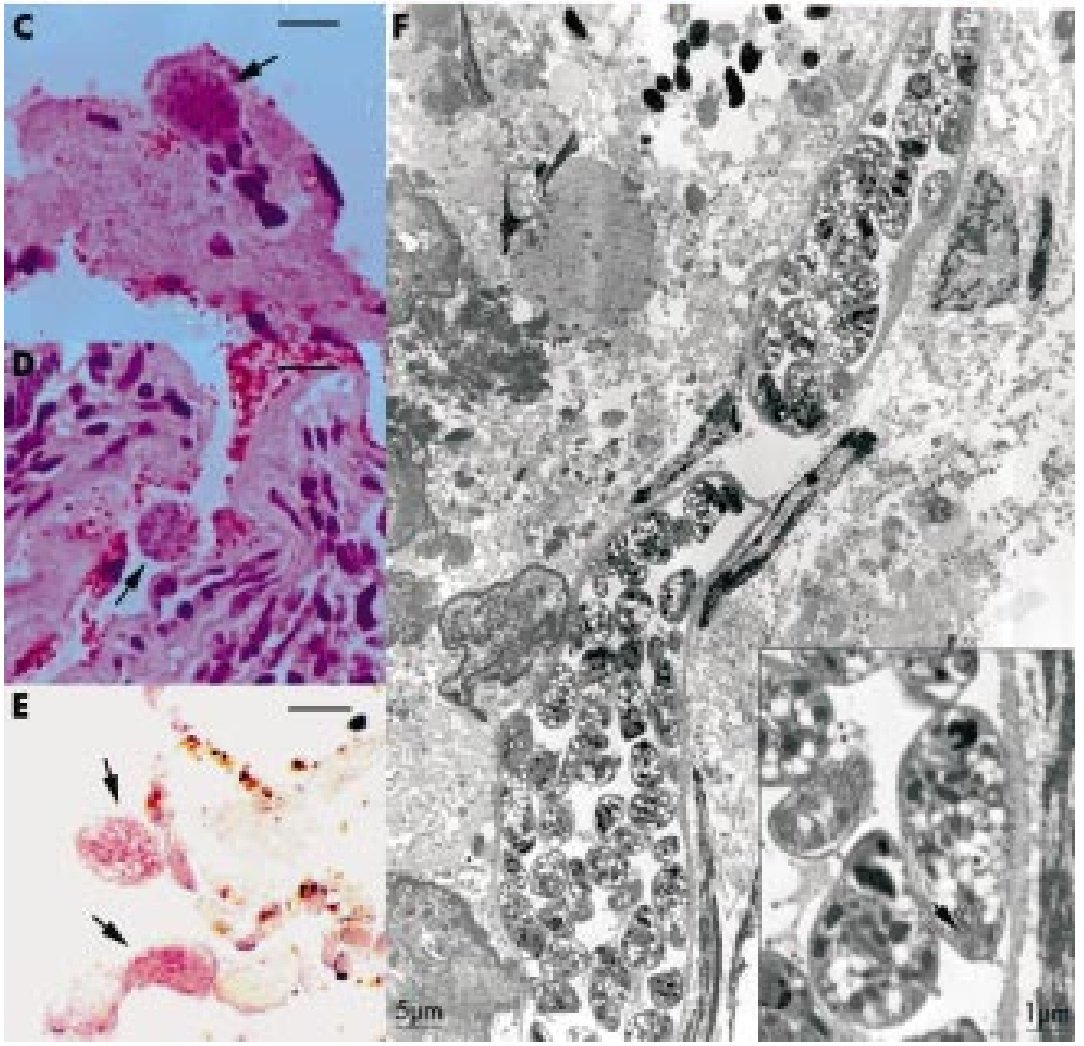

Figure 1 (A) Fundus appearance of the left eye. (B) Fundus appearance of the right eye. (C) Light micrograph shows necrotic retina with occasional inflammatory cells and Toxoplasma cyst (arrow). (D) Light micrograph shows the necrotic retinal pigment epithelium with Toxoplasma cysts (arrow) and the choroid with a dense infiltrate of lymphocyte and plasma cells (haematoxylin and eosin, bar $=10 \mu \mathrm{m})$. (E) Immunohistochemistry with alkaline phosphatase. Two Toxoplasma cysts (arrows) positively dyed pink (bar $=10 \mu \mathrm{m})$. (F) Electron micrograph of a paraffin embedded tissue post processed for electron microscopy of the chorioretinal biopsy shows two Toxoplasma cysts with micronemes (inset, arrow) and white spherules with hazy borders amylopectin granules (inset, asterisk). The inset shows higher magnification of a bradizoite, showing typical apical structures. Magnification is represented in standard bars. 
Based on these results, aciclovir was discontinued and oral anti-Toxoplasma treatmen was initiated with pyrimethamine, sulfadiazine, and folinic acid supplementation. After a 1 month treatment retinal lesions started to heal, yet no improvement of visual acuity was observed.

\section{Comment}

The present case was atypical because of an extensive bilateral necrotising retinitis and obliterative vasculitis, with no pre-existing chorioretinal scars. Three factors could have conferred a mild degree of immunosuppression to this patient: SLE, diabetes mellitus, ${ }^{6}$ and prednisone at medium dose. $^{8}$ It is recognised that retinal vasculitis and immunosuppression increase the risk of a herpetic and, to a lesser extent, a toxoplasmic, infection. Ocular toxoplasmosis associated with collagen vascular disorders is a rare event ${ }^{10}$ and has been described after aggressive immunosuppressive therapy. On the other hand, retinal vasculitis occurs in less than $10 \%$ of SLE patients, particularly in those presenting with antiphospholipid syndrome, which makes them susceptible to retinal infection. ${ }^{11}$ In the present case, laboratory findings consistent with antiphospholipid syndrome were absent. The pre-existence of widespread SLE retinal vasculopathy could be inferred by the active lupus central nervous system disease. ${ }^{12}$ Therefore we speculate that the active SLE associated with diabetes mellitus and the use of corticosteroid increased the patient's susceptibility to infection leading to this atypically severe ocular toxoplasmosis.

The causative agent was initially diagnosed as $T$ gondii based on PCR analysis of a vitreous sample and confirmed by histopathological findings of the chorioretinal biopsy. In the present case, the biopsy was also useful to discharge any tumoral infiltration. ${ }^{13}$ Although the local production of anti-Toxoplasma antibodies is also considered a useful parameter, the high intraocular total IgG titre found in this case, probably caused by a breakdown of the blood-aqueous barrier, was responsible for the false negative Desmont's coefficient. The simple observation of Toxoplasma cysts is not indicative of active infection. However, the presence of multiple cysts, aside from positive immunohistochemistry test in a symptomatic patient, allowed an accurate diagnosis.

Taking into account that the fundus characteristics strongly suggested a herpetic acute retinal necrosis, one could interpret the PCR as being a false negative result because of both, either a previous aciclovir treatment ${ }^{14}$ or a lack of sensitivity. Nevertheless, the disease progression despite antiviral therapy, the absence of any viral particles on electron microscopy, in conjunction with all the evidence pointing to a toxoplasmic retinitis makes the possibility of a combined infection still possible, but remote.

Based on the present case that showed an atypically severe form of ocular toxoplasmosis in a patient with a vasculopathy because of collagen and metabolic vascular disorders, we suggest that cases of severe necrotising retinitis be evaluated expeditiously to exclude conditions that mimic ARN. A less invasive vitrea PCR and, when indicated, an early retinochoroidal biopsy may yield a definite diagnosis avoiding any delay in introducing effective treatment.

\section{Acknowledgements}

This study was supported by FAPESP no 98/00256-3. Dr Heitor Franco de Andrade Junior of the Laboratory of Parasitic Diseases, University of São Paulo
School of Medicine, provided helpful suggestions for revision of the manuscript.

\section{J H Yamamoto, D I Boletti, Y Nakashima,} C E Hirata, E Olivalves Department of Ophthalmology, University of São Paulo School of Medicine, São Paulo, São Paulo

M M Shinzato

Department of Rheumatology, University of São Paulo School of Medicine, São Paulo, São Paulo

Brazil

T S Okay

Department of Pediatrics, LIM 36, University of São Paulo School of Medicine, São Paulo, São Paulo

Brazil

R M Santo

Departments of Ophthalmology and Pathology, University of São Paulo School of Medicine, São Paulo, São Paulo, Brazil

M I S Duarte

Department of Pathology, University of São Paulo School of Medicine, São Paulo, São Paulo, Brazi

J Kalil

Department of Allergy and Immunopathology and Laboratory of Immunology, InCor, University of São Paulo School of Medicine, São Paulo, São Paulo

Correspondence to: Joyce Hisae Yamamoto, MD $\mathrm{PhD}$, Av Dr Eneas Carvalho Aguiar $5003^{\circ}$ andar, CEP 05403-000 São Paulo SP Brazil joycehy@uol.com.br

Accepted for publication 25 September 2002

\section{References}

1 Holland GN. Ocular toxoplasmosis in the immunocompromised host. Int Ophthalmol 1989:13:399-402.

2 Sabates R, Pruett RC, Brochkurst RJ. Fulminant ocular toxoplasmosis. Am J Ophthalmol 1981;92:497-503.

3 Girard P, Kohen D, Chevalier C, et al. Necrose retinienne aigue et toxoplasmose oculaire. Bull Soc Ophtalmol

1984:84:751-4.

4 Tan EM, Cohen AS, Fries AS, et al. The 1982 classification criteria of systemic lupus erythematosus (SLE). Arthritis Rheum 1982:25:1271-7.

5 Wilson WA, Gharavi AE, Koike T, et al International consensus statement on preliminary classification criteria for definite antiphospholipid syndrome: report on an international workshop. Arthritis Rheum 1999;42:1309-1 1

6 Moutschen MP, Scheen AJ, Lefebvre PJ. Impaired immune responses in diabetes mellitus: analysis of the factors and mechanisms involved. Relevance to the increased susceptibility of diabetic patients to specific infections. Diabete Metab 1992; 18:187-201.

7 Johnson, MW, Greven, CM, Jaffe, GJ, et al. Atypical, severe toxoplasmic retinochoroiditis in elderly patients. Ophthalmology 1997; 104:48-57.

8 Nicholson D, Wolchok E. Ocular toxoplasmosis in an adult receiving long-term corticosteroid therapy. Arch Ophthalmol 976;94:248-54

9 Rappaport KD, Tang WM. Herpes simplex virus type 2 acute retinal necrosis in a patien with systemic lupus erythematosus. Retina 2000;20:545-6.

10 Held R, Eckardt C. Bilateral traction detachment in necrotizing retinitis as a sequela of toxoplasmosis. Fortschr Ophthalmol 1990;87:206-8.

11 Klinkhoff AV, Beattie CW, Chalmers A. Retinopathy in systemic lupus erithematosus: relationship to disease activity. Arthritis Rheum 1986;29:1152-6.

12 Stafford-Brady FJ, Urowitz MB, Gladman $\mathrm{DD}$, et al. Lupus retinopathy. Patterns, association and prognosis. Arthritis Rheum 1988;31:1105-10.

13 Topilow HW, Ackerman Al, Friedman A Progressive outer retinal necrosis (letter) Ophthalmology 1995;102:1737-8.

14 Toyoda M, Carlos JB, Galera OA, et al. Correlation of cytomegalovirus DNA levels with response to antiviral therapy in cardiac and renal allograft recipients. Transplantation 1997:63:957-63.

\section{Idiopathic dilated episcleral veins and increased intraocular pressure}

Intraocular pressure (IOP) is dependent on the rate of aqueous production, facility of outflow, and episcleral venous pressure. Increased IOP and visual field loss may result from an elevation of episcleral venous pressure, the causes of which include large vessel venous obstruction (venous sinus thrombosis and superior vena cava syndrome), arteriovenous shunts or fistulas, Sturge-Weber syndrome, scleritis, thyroid related orbitopathy, and orbital tumours. ${ }^{1}$ Increased episcleral venous pressure may result in elevated IOP and optic neuropathy, even in the absence of these entities. We report a 34 year old man with idiopathic dilated episcleral veins (IDEV) and increased IOP, with visual field loss.

\section{Case report}

A 34 year old man presented for neuroophthalmic evaluation because of decreased vision in the right eye and injection of both eyes. His intraocular pressure (IOP) had been elevated in the right eye more than the left for the past 13 years, reaching $32 \mathrm{~mm} \mathrm{Hg}$ in the right eye. His eyes appeared red for as long as he could remember, but details of his previous ophthalmic examinations were unavailable. Because of the bilateral injection he saw two other neuro-ophthalmologists, who suspected an arteriovenous fistula. One year before presentation he underwent magnetic resonance imaging (MRI) of the head and orbits and catheter arteriography on two occasions, which were both normal. He had no other previous medical problems, was taking no
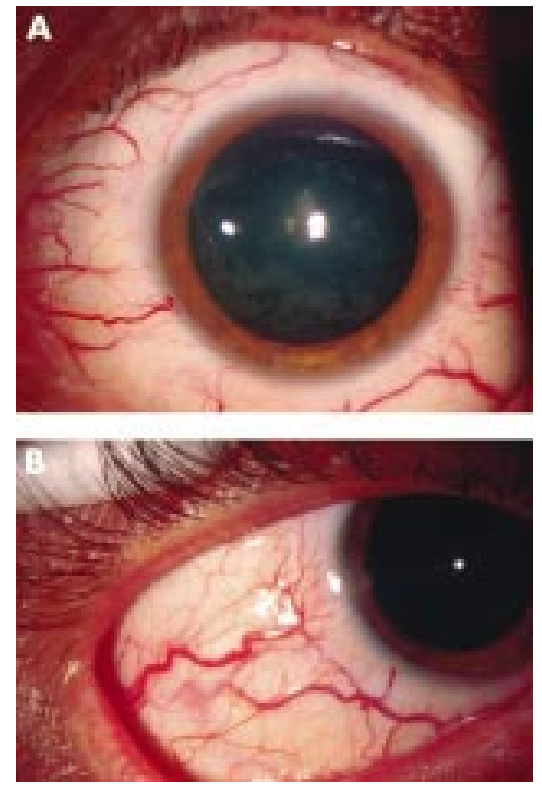

Figure 1 External examination shows dilated episcleral veins of each eye. (A) Right eye, (B) left eye. 

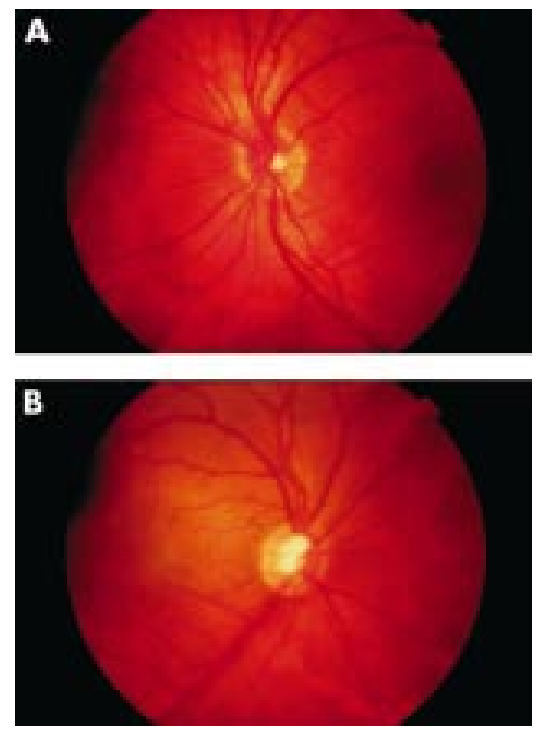

Figure 2 The left optic disc $(A)$ is normal and the right optic disc (B) shows a vertically elongated cup. The retinal vessels are of normal calibre.

drugs, and had no recent history of trauma to the head or neck.

External examination revealed no evidence of cutaneous angiomatosis. Best corrected visual acuity was $20 / 25$ in the right eye and 20/20 in the left eye. Although he correctly identified eight of eight Ishihara pseudoisochromatic colour plates with each eye, he had a $35 \%$ subjective red desaturation on the right, with a right relative afferent pupillary defect (RAPD). There was no exophthalmos and no increased resistance to retropulsion of the globes into the orbits. Dilated episcleral veins were apparent in each eye (Fig 1), while the conjunctival vessels were normal. Intraocular pressure was $22 \mathrm{~mm} \mathrm{Hg}$ on the right and 16 $\mathrm{mm} \mathrm{Hg}$ on the left, and the mires of the Goldmann applanation tonometer were normally pulsatile. Gonioscopy revealed bilaterally open iridocorneal angles to the ciliary body band for 360 degrees with blood in the canals of Schlemm in both eyes, greatest within the inferior 90 degrees, but without evidence of

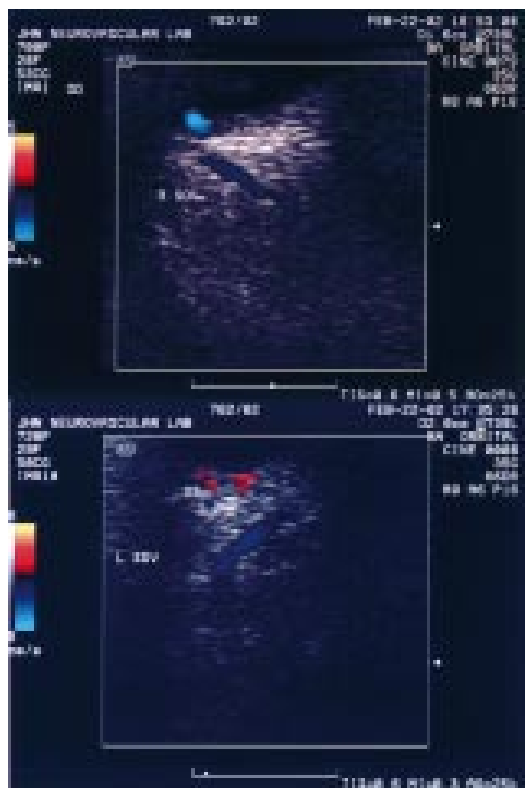

Figure 3 Orbital colour Doppler imaging shows a normal calibre of the superior ophthalmic veins in the right (A) and left (B) orbits. The blue colour represents normal retrograde flow of the orbital veins.

neovascularisation or angle recession. Automated perimetry revealed a nasal step on the right and decreased sensitivity inferiorly on the left. Asymmetric cupping of the optic disc with vertical elongation on the right, was noted on funduscopy (Fig 2).

Orbital colour Doppler imaging revealed normal flow parameters in the ophthalmic and central retinal arteries of each eye. The superior ophthalmic vein was of normal calibre and there was no evidence of reversal of flow in either orbit (Fig 3).

\section{Comment}

Arteriovenous fistula is the most frequent cause of ocular injection with increased IOP due to elevated episcleral venous pressure..$^{1-3}$ The ocular injection results from engorged, arterialised conjunctival vessels, ${ }^{45}$ which is different from the injection seen in IDEV
Traumatic high flow fistulas may present with proptosis, eyelid oedema, and conjunctival chemosis, and are often easily identified clinically. Spontaneous, frequently low flow fistulas may present with progressive unilateral or bilateral injection, and may be more difficult to diagnose.

There is, however, an infrequent syndrome of ocular injection and increased IOP which is idiopathic. Although originally described by Minas and Podos, ${ }^{6}$ the same entity is termed the Radius-Maumenee syndrome ${ }^{7}$ in the German literature. ${ }^{189}$ In one report 10 of 64 patients with glaucoma due to elevated episcleral venous pressure had this syndrome. ${ }^{1}$ In another report of six patients with unilateral dilated episcleral veins and one patient with bilateral involvement, the IOP in the affected eyes ranged between 21 and $44 \mathrm{~mm} \mathrm{Hg.{ } ^ { 1 0 }}$ In all six patients with apparently unilateral involvement the IOP was higher in the eye with the dilated vessels. Episcleral venous pressure was measured to be twice the normal value in the affected eyes of these patients.

Catheter arteriography in these patients is normal, without abnormal arteriovenous communications. ${ }^{10}$ "1 Other adjunctive testing, including neuroimaging, orbital venography, and fluorescein angiography are also normal. ${ }^{9}$ Although abnormalities in ocular blood flow have been suggested, the pathogenesis of this condition remains unclear

Orbital colour Doppler imaging provides a non-invasive means of imaging orbital and ocular blood flow and, in patients with fistulas, characteristically shows reversal of blood flow in a dilated superior ophthalmic vein. ${ }^{12}$ The superior ophthalmic veins were of normal calibre in our patient, and both orbits showed normal retrograde flow in the orbital veins. Similar findings were reported in the only other patient with this syndrome who underwent orbital colour Doppler imaging, and increased arterial and venous flow in the episcleral vessels was noted in the eye with dilated episcleral vessels; however, the images of the ultrasonography were not published. ${ }^{11}$ We did not measure the episcleral blood flow in our patient.

Although the cause of this disorder remains elusive it should be distinguished from other disorders, most commonly the arteriovenous fistula (Table 1), which can result in dilated episcleral vessels and increased IOP. In patients with IDEV a congenital abnormality in

Table 1 Differentiating features of arteriovenous fistula and IDEV and increased IOP

\begin{tabular}{|c|c|c|}
\hline & Arteriovenous fistula & Idiopathic dilated episcleral veins (IDEV) \\
\hline Onset & Most often acquired & May be congenital \\
\hline Predisposing factors & Trauma, hypertension & Possible familial predisposition \\
\hline Symptoms & Pulsatile bruit or tinnitus, pain, diplopia & None \\
\hline Neurological signs & $\begin{array}{l}\text { Ocular misalignment, unilateral or bilateral sixth nerve } \\
\text { paresis, oculomotor paresis }\end{array}$ & None \\
\hline External examination & $\begin{array}{l}\text { Dilated, corkscrew conjunctival and episcleral vessels, } \\
\text { conjunctival chemosis, eyelid oedema, proptosis }\end{array}$ & Dilated episcleral veins, conjunctival vessels of normal calibre \\
\hline Anterior segment & $\begin{array}{l}\text { Cataract, iris, and angle neovascularisation with orbital } \\
\text { ischaemic syndrome }\end{array}$ & Normal \\
\hline Orbital signs & Bruit, proptosis & None \\
\hline Goldmann tonometry & Abnormally pulsatile mires & Normally pulsatile mires \\
\hline Funduscopy & $\begin{array}{l}\text { Dilated, engorged retinal vessels. Occasionally ocular } \\
\text { ischaemic syndrome, with optic disc oedema and } \\
\text { macular oedema. Rarely central retinal vein occlusion. } \\
\text { Rarely optic disc cupping }\end{array}$ & Optic disc cupping \\
\hline Imaging & Dilated superior ophthalmic vein or cavernous sinus & Normal \\
\hline OCDI & $\begin{array}{l}\text { Dilated superior ophthalmic veins with reversal of orbital } \\
\text { venous flow }\end{array}$ & Normal \\
\hline Catheter angiography & Arteriovenous fistula & Normal \\
\hline
\end{tabular}


vasculature and familial predisposition have been suggested as the cause ${ }^{7}$; however some reports suggest that the ocular injection is acquired..$^{10}$

Treatments have focused on reducing IOP with aqueous suppression. Filtration surgery has been favoured by some, and in one patient who underwent trabeculectomy the IOP was reduced but the dilated episcleral veins remained unchanged. ${ }^{11}$ Presumably an alteration in aqueous outflow would preclude the use of IOP lowering agents which increase uveoscleral outflow; however, the earlier reports of IDEV preceded the availability of these agents.

Although no clear aetiology has been identified for IDEV, the findings in this syndrome have been characterised well enough to obviate the need for catheter angiography in patients with the clinical features of this syndrome who have normal orbital colour Doppler imaging, and to avoid delaying the treatment of elevated IOP.

\section{Acknowledgement}

Dr Foroozan is supported by the Heed Ophthalmic Foundation, Cleveland, Ohio, USA

The authors have no proprietary interest in any contents within this manuscript.

\section{R Foroozan, L M Buono, P J Savino,}

R C Sergot

Neuro-Ophthalmology Service, Wills Eye Hospital Thomas Jefferson University, 900 Walnut Street, Philadelphia, PA 19107, USA

Correspondence to: P J Savino

Neuro-Ophthalmology Service, Wills Eye Hospital,

Thomas Jefferson University, 900 Walnut Street,

Philadelphia, PA 19107, USA; pjsavino@aol.com

Accepted for publication 30 September 2002

\section{References}

1 Jorgensen JS, Guthoff R. Die rolle des episkleralen venendrucks bei der enstehung von sekundarglaukomen [The role of episclera venous pressure in the development of secondary glaucomas]. Klin Monatsbl Augenheilkd 1988;193:471-5.

2 Henderson JW, Schneider RC. The ocular findings in carotid-cavernous fistula in a series of 17 cases. Am J Ophthalmol 1959;48:585-97.

3 Brismar G, Brismar J. Spontaneous carotid-cavernous fistulas. Clinical symptomatology. Acta Ophthalmol (Copenh) 1976;54:542-52.

4 Keltner JL, Gittinger JW Jr, Miller NR, et al. $A$ red eye and high intraocular pressure. Surv Ophthalmol 1987;31:328-36.

5 Keltner JL, Satterfield D, Dublin AB, et al. Dural and carotid cavernous sinus fistulas. Diagnosis, management, and complications. Ophthalmology 1987;94:1585-600.

6 Minas TF, Podos SM. Familial glaucoma associated with elevated episcleral venous pressure. Arch Ophthalmol 1968;80:202-8.

7 Radius RL, Maumenee AE. Dilated episcleral vessels and open-angle glaucoma. Am J Ophthalmol 1978;86:31-5.

8 Groh MJ, Kuchle M. Idiopathische episklerale venenstauung mit sekundarem offenwinkelglaukom

(Radius-Maumenee-syndrome) [Idiopathic episcleral venous stasis with secondary open-angle glaucoma (Radius-Maumenee syndrome)]. Klin Monatsbl Augenheilkd syndrome)]. Klin Mond

9 Jorgensen JS, Guthoff R. Zur genese der einseitig dilatierten episkleralen GefaBe und erhohung des intraokularen drucks

[Pathogenesis of unilateral dilated episcleral vessels and increase in intraocular pressure]. Klin Monatsbl Augenheilkd 1987; 190:428-30

10 Talusan ED, Fishbein SL, Schwartz B. Increased pressure of dilated episcleral veins with open-angle glaucoma withou exophthalmos. Ophthalmology 1983;90:257-65

11 Lanzl IM, Welge-Luessen U, Spaeth GL. Unilateral open-angle glaucoma secondary to idiopathic dilated episcleral veins. Am J Ophthalmol 1996;121:587-9.

12 Flaharty PM, Lieb WE, Sergott RC, et al Color Doppler imaging. A new noninvasive technique to diagnose and monitor carotid cavernous sinus fistulas. Arch Ophthalmol 1991;109:522-6.

\section{Trypan blue assisted descemetorhexis for inadvertently retained Descemet's membranes after penetrating keratoplasty}

The presence of a retrocorneal membrane following an uneventful keratoplasty is a known entity. ${ }^{2}$ While the inflammatory membranes usually disappear with the use of topical steroids $^{3}$ a YAG laser treatment has been used to make an opening in the opacified retained membrane. We describe a new technique of removal of retained Descemet's membrane using trypan blue dye.

Case 1

A 27 year old man underwent penetrating keratoplasty in his left eye for congenita hereditary endothelial dystrophy (CHED). The host cornea was initially trephined to $90 \%$ of the corneal depth with a $7.5 \mathrm{~mm}$ trephine (Storz Ophthalmics, St Louis, MO, USA). The anterior chamber was entered with a blade and the host cut was completed with corneal scissors. An $8 \mathrm{~mm}$ donor button was anchored with 16 interrupted sutures (10-0 monofilament nylon). On the first postoperative day, slit lamp biomicroscopy revealed a retained Descemet's membrane and a supernumerary anterior chamber. The graft was clear with a best corrected visual acuity (BCVA) of 20/40.

At 1 week, an additional inflammatory membrane was detected between the retained Descemet's membrane and iris at 6 o'clock position extending from the inferior margin up to the lower third of the anterior chamber (Fig 1). The inflammatory membrane did not resolve with increased frequency of topical steroid and at 4 weeks we decided to excise these membranes.

The 10 o'clock and the 11 o'clock sutures were removed and the graft host junction was separated. Under air, $0.1 \mathrm{ml}$ of $0.1 \%$ trypan blue (Vision blue, DORC, Netherlands) was injected over the host's retained Descemet's membrane and was left in contact with it for 10 seconds and then washed out. Both retained Descemet's membrane and inflammatory membranes were stained with the

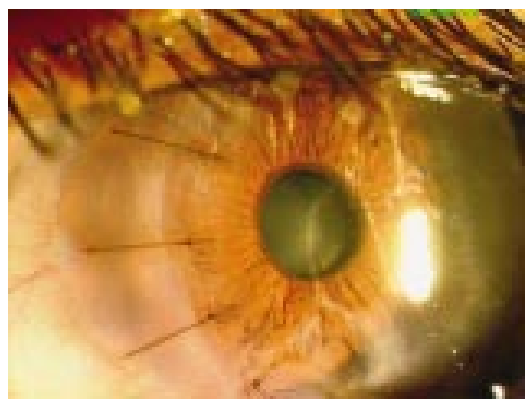

Figure 1 Double anterior chamber in case 1 with congenital hereditary endothelial dystrophy. dye. The inflammatory membrane was first removed using a Utrata forceps. Subsequently, a small flap was created in the retained Descemet's membrane and the membrane was torn in a circular fashion (Fig 2). The anterior chamber was reformed and sutures were reapplied. On the first postoperative day the graft was clear, the anterior chamber was well formed, and there was no retrocorneal membrane.

Case 2

A 26 year old man underwent penetrating keratoplasty in his right eye for CHED with the same surgical technique and graft size as in first case. On the first postoperative day, a transparent retained Descemet's membrane along with formation of a supernumerary chamber was detected on slit lamp biomicroscopy. The graft was clear with no active inflammation in the anterior chamber and BCVA was 20/40.

Based on our experience of case 1 regarding the development of inflammatory membrane, we decided to excise the retained Descemet's membrane at 1 week using the same technique. Postoperatively, slit lamp biomicroscopy did not reveal any evidence of supernumerary chamber or retrocorneal membrane.

Postoperatively, the patients received 2 hourly $0.1 \%$ betamethasone sodium phosphate eye drops, $0.3 \%$ ciprofloxacin eye drops four times daily and preservative-free artificial tears eye drops four times daily. At 2 months of follow up, the grafts were clear with a single anterior chamber and the visual acuity of 20/40 was maintained in both the eyes.

\section{Comment}

Both these cases with retained host Descemet's membrane following penetrating keratoplasty were that of CHED. In these cases, longstanding stromal oedema may cause loosening of the attachment of the Descemet's membrane and predispose its separation from the overlying stroma as has also been reported in a case of interstitial keratitis. ${ }^{4}$ Hence, inadvertent, incomplete trephination of such oedematous corneas may cause retention of the host Descemet's membrane. Although both the patients had good vision and the grafts and retrocorneal membranes were clear, we decided to excise these membranes as an inflammatory membrane started growing in the first case. We thought that the host's retained Descemet's membrane is acting as a scaffold and further growth of inflammatory membranes may jeopardise the graft.

Trypan blue is commonly used to stain the anterior lens capsule for capsulorhexis in cataract surgery. ${ }^{5}$ As both lens capsule and

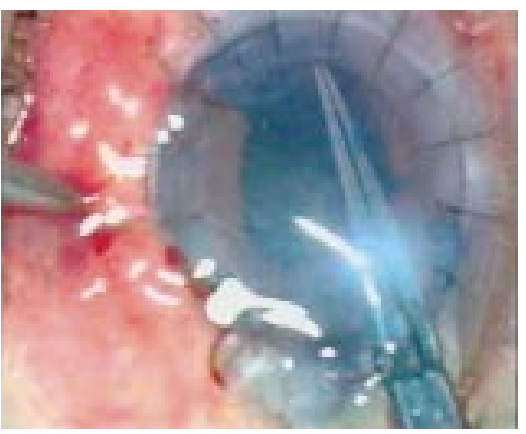

Figure 2 Trypan blue assisted descemetorhexis in case 1. 
Descemet's membrane are basement membranes, we attempted to stain the retained Descemet's layer with trypan blue to enhance its visibility during the surgery. In both the cases an optimal staining of the membranes helped in achieving a controlled circular tearing of the membrane without affecting graft clarity.

We called our technique of dye assisted removal of retained Descemet's membrane "descemetorhexis" as the retained Descemet's membrane were torn in a circular fashion a the graft-host junction.

R Sinha, R B Vajpayee, N Sharma, J S Titiyal, R Tandon Rajendra Prasad Center for Ophthalmic Sciences, All India Institute of Medical Sciences, New Delhi,

India

Correspondence to: Rasik B Vajpayee, MBBS, MS RP Centre for Ophthalmic Science, All India Institute of Medical Sciences, New Delhi - 110029 India; rasikvaipayee@rediffmail.com

Accepted for publication 9 October 2002

\section{References}

1 Leigh AG. Complications of corneal grafting. In: Trevor-Roper PD, ed. Diseases of the cornea. International ophthalmology clinics.

Vol 2. No 3. Boston: Little, Brown, 1962:757.

2 Lazar M, Loewenstein A, Geyer O. Intentional retention of descemet's membrane during keratoplasty. Acta Ophthalmol Copenh 1991;69:111-12.

3 Lifshitz T, Oshry T, Rosenthal G. Retrocorneal membrane after penetrating keratoplasty. Ophthal Surg Lasers 2001;32:159-61.

4 Henderson JW, Wolter RJ. Separation of Descemet's membrane in keratoplasty. Am J Ophthalmol 1968;65:375-8.

5 Melles GRJ, de Waard WT, Pameyer JH, et al. Trypan blue capsule staining to visualize the capsulorhexis in cataract surgery. J Cataract Refract Surg 1999;25:7-9.

\section{Orbital haemorrhage complication following postoperative thrombolysis}

Thrombolytic agents, such as tissue plasminogen activator (tPA), are commonly employed early in the management of patients with acute myocardial infarction. In this setting the rapid thrombolysis of coronary thrombi achieves reperfusion and has well established survival benefits. ${ }^{1}$ Often the anticoagulant heparin is simultaneously administered to prevent reocclusion. ${ }^{1}$ Both therapies may have haemorrhagic complications. We report a case of retrobulbar haemorrhage as a complication of thrombolytic therapy instituted for an acute myocardial infarction occurring 2 days after routine cataract surgery.

\section{Case report}

A 72 year old man underwent uncomplicated right phacoemulsification and posterior chamber intraocular lens implantation. Before surgery, a peribulbar block was administered, using a single transcutaneous inferior lateral injection of local anaesthetic. The patient had a background of hypertension and hypercholesterolaemia. His medications included amlodipine besylate, simvastatin and aspirin. The aspirin had been stopped 1 week before surgery. The patient had no pas medical history of a haematological disorder. Two months previously he had undergone uneventful left sided cataract surgery.

The day 1 postoperative ocular examination was unremarkable and the patient was generally well. Two days following surgery the patient was admitted to the emergency

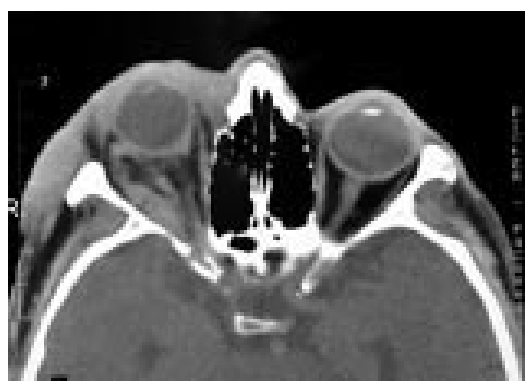

Figure 1 Computed tomograph scan showing a large retrobulbar haematoma near the lateral rectus muscle.

department with an acute inferolateral myocardial infarct. The attending cardiologist and the patient's ophthalmologist agreed that the benefits of thrombolysis outweighed the risk to the eye and vision. A 10 unit dose of tPA was administered to the patient with a concomitant heparin infusion; this was followed half an hour later by a second dose. Aspirin was also prescribed.

Two hours after the initial dose of tPA periorbital swelling of the right eye was noted Over the next hour there was increasing periorbital oedema and the patient reported mild ocular discomfort, loss of vision, nausea, and vomiting. During one episode of emesis there was an abrupt onset of frank periocular haemorrhage. The heparin infusion was stopped. Examination of the affected eye revealed proptosis, subconjunctival haematoma, a relative afferent pupillary defect, a hazy cornea, and severely restricted extraocular movements. Vision was no perception of light. A computed tomograph scan demonstrated a large retrobulbar haematoma in proximity of the lateral rectus muscle (Fig 1). The patient was given intravenous acetazolamide and hydrocortisone. Canthotomy and cantholysis resulted in a slight improvement in adduction and abduction of the eye, however vision remained at no perception of light.

With the heparin ceased the patient was at increased risk of recurrent thrombosis and that evening was transferred to a centre with a cardiac catheterisation laboratory and for review by an orbital surgeon. The following day, after urgent coronary angiography, it was considered unsafe for the patient to proceed to decompressive orbitotomy while untreated for his coronary artery disease. The probability that eyesight would return thereafter was considered remote and the retrobulbar haemorrhage was managed conservatively. The patient underwent coronary angioplasty with placement of a stent and placed on clopidogrel and aspirin.

Bleeding of the right orbit continued for a further 48 hours; thereafter extraocular movements gradually improved, periorbital oedema subsided, and the degree of proptosis reduced. On discharge, 8 days after admission, vision remained at no perception of light.

\section{Comment}

Haemorrhage represents the most common and important complication of thrombolytic therapy. ${ }^{1}$ Relative contraindications to the use of thrombolytic agents include major surgery in the previous 3 weeks and non-compressible vascular punctures.

There are several reports of postoperative haemorrhagic ocular complications following the use of systemic thrombolytic agents including a total hyphaema following streptokinase administration 8 days after extracapsular cataract extraction, ${ }^{2}$ sub-Tenon's haemorrhage following streptokinase given 2 hours after scleral buckling surgery, ${ }^{3}$ and three cases of orbital haemorrhage following thrombolytic therapy administered within 1-5 days after cataract or eyelid surgery. ${ }^{45}$

The retrobulbar haemorrhage in our patient is most likely the result of thrombolytic therapy and the result of lysis of a haemostatic plug in an arterial vessel within the orbit that was punctured during the delivery of the anaesthetic. ${ }^{4}$ Reformation of a haemostatic plug was probably inhibited by the antiplatelet and anticoagulant effects of aspirin and heparin.

Prompt recognition and immediate delivery of appropriate treatment are important in the preservation of good visual acuity. ${ }^{3}$ In our case lateral cantholysis did not adequately relieve the retro-orbital haemorrhage. The extent of our patient's coronary artery disease precluded the general anaesthetic necessary for orbitotomy and, because of its life threatening nature, its management took precedence.

Pertinent in the consideration of decompressive orbitotomy was the presence of any ongoing systemic effects of tPA, heparin, and aspirin. The circulating half life of tPA is 6 minutes, although the duration of the local lytic effect from fibrin bound tPA is not known. ${ }^{1}$ The effective biological half life of heparin is approximately 1 hour. ${ }^{6}$ Many hours after their last administration, neither was likely to be having any ongoing systemic effects of concern. The duration of action of aspirin, however, continues for the life of affected platelets, 7-10 days, as it irreversibly inhibits the enzyme responsible for platelet aggregation. ${ }^{1}$ This effect gradually dissipates as new platelets are formed. Although not necessarily prohibitive to surgery, the implications of ongoing platelet dysfunction include difficulty in achieving haemostasis with the potential for poor surgical visualisation and extensive blood loss.

Primary percutaneous transluminal coronary angioplasty (PTCA) may be performed as an alternative to thrombolytic therapy. With improved mortality and lower rates of intracranial haemorrhage, primary PTCA would seem an attractive alternative especially in those patients at high risk of haemorrhage. However, it should be noted that a case of orbital haemorrhage following PTCA has also been reported. ${ }^{8}$

This patient originally had bilateral cataracts and 2 months earlier had undergone uneventful left sided cataract surgery. Had the cataract operations been conducted in close succession, a similar situation as described here may have presented the potential for complete blindness. Although rare, such unforseen circumstances may need to be considered when determining optimal timing of successive surgery for bilateral cataracts.

This case highlights that, in the context of relative contraindications to thrombolytic therapy, cataract surgery with injected local anaesthesia is to be considered major surgery. Thrombolytic therapy required shortly after cataract surgery has the potential to result in sight threatening haemorrhagic complications.

The authors hold no financial or proprietary interest in any product mentioned in this letter.

J K Leong, R Ghabrial, P J McCluskey Department of Ophthalmology, Royal Prince Alfred Hospital, Sydney, Australia 
S Mulligan

Department of Ophthalmology, Bankstown Hospital, Sydney, Australia

Correspondence to: Peter McCluskey, FRACO, 357 Beamish Street, Campsie NSW 2194, Australia;

Accepted for publication 10 October 2002

\section{References}

1 Ryan TJ, Anderson JL, Antman EM, et al. Management of acute myocardial infarction. JACC 1996;28: 1328-428.

2 Cahane M, Ashkenazi I, Avni I, et al. Total hyphaema following streptokinase administration eight days after cataract extraction. Br J Ophthalmol 1990;74:447.

3 Marcus DM, Frederick AR Jr.

Streptokinase-induced Tenon's hemorrhage after retinal detachment surgery. Am J Ophthalmol 1994;118:815-17.

4 Chorich LJ, Derick RJ, Chambers RB, et al. Hemorrhagic ocular complications associated with the use of systemic thrombolytic agents. Ophthalmology 1998;105:428-31.

5 Yuen VH, Dolman PJ. Postoperative orbital hemorrhage following thrombolysis for acute myocardial infarction. Can J Ophthalmol 1999;34:33-5.

6 Hoffbrand AV, Pettit JE. Essential haematology. 3rd ed. Oxford: Blackwell Science, 1993:356

7 GUSTO Ilb. The Global Use of Strategies to Open Occluded Arteries in Acute Coronary Syndromes Angioplasty Substudy Investigators. A clinical trial comparing coronary angioplasty with tissue plasminogen activator for acute myocardial infarction. $N$ Engl J Med 1997;336:1621-8.

8 Andreou P, Wintle R, Brazier J. Spontaneous orbital haemorrhage following cardiac angioplasty. Br J Ophthalmol 2001;85:1012.

\section{The IOL flip: rescue for foldable lens implantation gone wrong}

Phacoemulsification surgery offers many advantages in comparison with extracapsular cataract extraction (ECCE). In particular, faster visual rehabilitation and better contro over surgically induced astigmatism are well established benefits over ECCE. ${ }^{12}$ These advantages are largely due to the small size of the cataract incision.

Inadvertent insertion of a posterior chamber intraocular lens (IOL) with a reversed front to back orientation is a surgical dilemma that will present occasionally. Anecdotal evidence suggests that while this problem is not common, it is not a rare event. Reported data place the frequency between $1.0-1.3 \%{ }^{4-6}$

Often, IOL inversion is only recognised after the optic has unfolded within the eye. The small phacoemulsification wound, while acting as an ally in the postoperative recovery of the patient, has in this situation become a foe to the surgeon. Faced with this situation, the surgeon has a few options. The simplest would be to leave the IOL inverted. Indeed, this has been advocated by some authors. ${ }^{4}$ The second would be lens explantation and exchange. However, this often involves sacrificing the $\mathrm{IOL}^{7}$ and is difficult to perform. Alternatively, enlarging the cataract incision to the size of the optic would allow extraction and reinsertion without damage to the IOL Unfortunately, this would diminish the benefits inherent within the small cataract wound. A better option would be to flip the IOL in situ without enlarging the wound, thus retaining all the advantages of small incision cataract surgery.

\section{Materials and methods}

This simple technique is easy to perform even for the first time, and has good repeatability. It

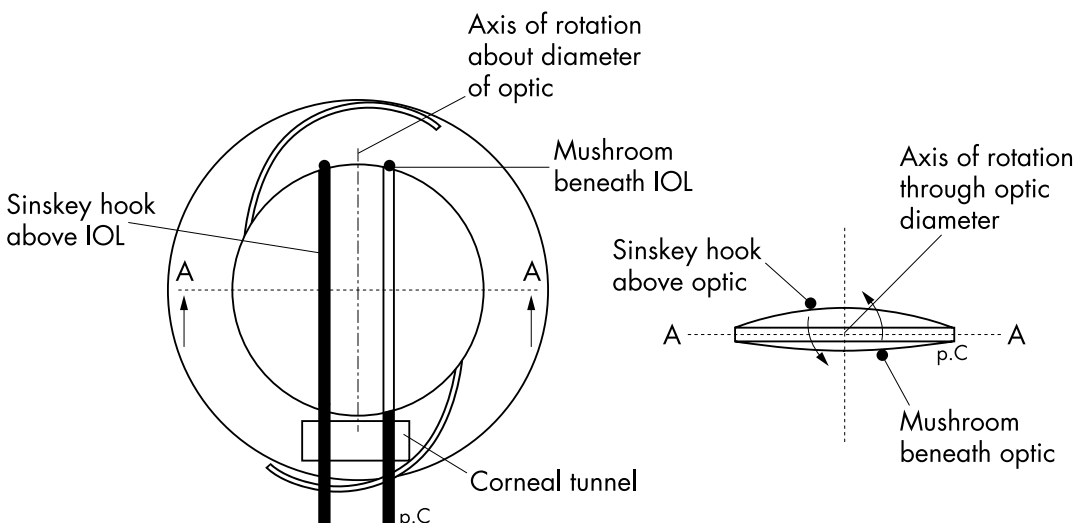

Figure 1 (A) Positioning of instruments for IOL flip. (B) Section through plane A-A.

is recommended only for soft foldable IOLs, and should not be used for rigid one piece poly(methyl methacrylate) (PMMA) lenses. PMMA IOL implantation is usually through an enlarged incision, and it would be simpler to dial out the superior haptic and reimplant the lens. The haptics of PMMA IOLs are also much stiffer than foldable IOLs and can damage both the posterior capsule and the endothelium during the flipping process. This manoeuvre is also not recommended for cases where the integrity of the capsular bag is lost or in doubt, as there is a potential for worsening any capsular rent.

The idea of the technique is to cause a rotational movement about the diameter of the IOL optic, similar to flipping a coin, while at the same time protecting the corneal endothelium and posterior capsule. The technique proceeds as follows:

(1) The anterior chamber is deepened with viscoelastic to create space between the optic haptics and the endothelium. The capsular bag behind the optic is distended with viscoelastic to facilitate safe flipping of the IOL

(2) This step flips the IOL. The rotational force on the optic is generated by the careful placement of two intraocular instruments. Non-sharp instruments are preferable, such as a Sinskey hook and mushroom. Their long horizontal segments ensure a controlled rotation of the optic about the central axis. For the right handed surgeon, a Sinskey hook held in the left hand is gently placed anterior to, and on the left of, the optic centre, while a mushroom in the right hand is placed behind the optic, to the right of the optic centre (Fig lA). To initiate the flip, the mushroom is then raised towards the cornea while simultaneously the Sinskey hook is pushed posteriorly. These movements take place about an axis passing through the diameter of the optic (Fig 1B), forcing the IOL to flip. The haptics then do a 180 degree slow, controlled sweep into the correct position, lagging slightly behind the optic. The manipulation should be completed in one smooth action. It is important to ensure that flipping occurs in the anticlockwise direction so that the leading haptic's free end does not point towards and threaten the posterior capsule. There is usually adequate room between the corneal endothelium and posterior capsule in most eyes to accommodate the vertical position of the optic during the flip. Although it is possible to perform this manoeuvre with the lens held by the KelmanMcPherson forceps, slight misalignment of the jaws, which often is present, could result in sudden and uncontrolled twisting and an uncontrolled flip so this is not recommended.

\section{Comment}

Most of the problems causing IOL inversion are related to inadequate attention to details during lens insertion. The use of injectable IOL systems, particularly those that require elaborate rotational movements on the part of the surgeon in order to correctly place the IOL into the capsular bag may result in an inverted IOL. Correct insertion of the IOL within the cartridge is no guarantee of correct placement into the eye. In the AMO Unfolder system, particular care has to be taken to avoid inversion. During injection, the free end of the leading haptic has to be directed to the surgeon's left, with the loop held in the horizontal position at all times via a series of pronation movements of the right handed surgeon's wrist, in order for the IOL to be correctly oriented. Failure to pronate the wrist in an adequate and timely fashion will result in an incorrect placement. Other systems that do not require complicated manipulations may reduce the possibility of incorrect implantation.

Forceps insertion of foldable IOLs also may lead to reversed placement. The correct orientation of the IOL should be checked before folding in all cases, particularly if the lens has been dropped during transfer. Incorrect orientation is indicated by an "S" configuration formed by the lens haptics and optic. Recognition of the "S" must signal to the surgeon to "stop" and check. Occasionally the trailing haptic may be trapped within the incision by the jaws of the inserting forceps, inducing spontaneous flipping within the eye. Recognised early, this can be aborted by placing the forceps tips over the optic to prevent further rotation, while releasing the trapped haptic with Kelman-McPherson forceps.

Although inverted lens implantation is eminently preventable with proper attention at each step of lens implantation, it still is a problem that occurs with enough frequency to be of concern. Should the surgeon decide that correction of the reversal is appropriate, the IOL flip offers a simple, quick and safe way out of a tight spot.

\section{Acknowledgements}

The authors are grateful to Paul Chua of the Medical Illustration Department of the Singapore National Eye Centre for his assistance with the illustrations.

C Y W Khng, K-T Yeo Singapore National Eye Centre 
Correspondence to: Dr Christopher Y W Khng Singapore National Eye Centre, 11 Third Hospital Avenue, Singapore 168751 cgkhng@yahoo.com.sg

Accepted for publication 22 October 2002

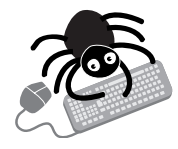

A video clip of the technique is available on the BJO website www.bjophthalmol.com/ supplemental

\section{References}

1 Naus NC, Luyten GP, Stiinen T, et al. Astigmatism and visual recovery after phacoemulsification and conventional extracapsular cataract extraction. Doc Ophthalmol 1995;90:53-9.

2 Cavallini GM, Lugli N, Campi L, et al. Surgically induced astigmatism after manual extracapsular cataract extraction or after phacoemulsification procedure. Eur $J$ Ophthalmol 1996;6:257-63.

3 Neumann AC, McCarty GR, Sanders DR, et al. Small incisions to control astigmatism during cataract surgery. J Cataract Refract Surg 1989;15:78-84

4 Halpern BL, Gallagher SP. Refractive error consequences of reversed-optic AMO SI-4ONB intraocular lenses. Ophthalmology 1999; 106:901-3.

5 Hagan JC 3rd. Initial experience with the Monarch $\mathrm{IOL}$ delivery system for insertion of the $5.5 \mathrm{~mm}$ Acrysof intraocular lens. Mo Med $1999: 96: 555,561-2$.
6 Olson R, Cameron R, Hovis $T$, et al. Clinical evaluation of the Unfolder. J Cataract Refract Surg 1997;23: 1384-9.

7 Koo EY, Lindsey PS, Soukiasan SH. Bisecting a foldable acrylic intraocular lens for explantation. $J$ Cataract Refract Surg 1996;22:(Suppl 2)1381-2.

\section{Recovery of visual function in a patient with birdshot chorioretinitis}

Birdshot chorioretinopathy (BSCR) is a rare inflammatory disease, which generally follows a chronic course of progressive loss of vision to $6 / 60$ or worse. ${ }^{1}$ However, the vision may stabilise ${ }^{1}$ or, rarely, improve slightly. Commonly prescribed treatment regimens, including oral steroids, and one or two immunosuppressive agents, may stabilise but generally do not cure the condition.

We describe a case of BSCR in which there was a marked improvement in Snellen acuity and retinal function, measured with wide field multifocal electroretinography (WFmfERG $),{ }^{45}$ in a patient intolerant of conventional treatment, who self medicated with an antioxidant preparation.

\section{Case report}

A 53 year old white woman was referred with a 2 year history of decreased vision and floaters affecting both eyes. Snellen acuity was $6 / 24$, N8 in the right eye and 6/12, N8 in the left eye. Moderate vitritis, cystoid macular oedema, swelling of the optic discs, and the presence of scattered, deep, pale creamy white lesions, were compatible with a diagnosis of BSCR, supported by positive HLA-A29 serology.

A reducing dose of oral prednisolone in conjunction with cyclosporin was commenced. There was no improvement in visual symptoms and, owing to the development of cellulitis around the umbilicus, cyclosporin was stopped.

She was referred to the regional uveitis service. WF-mfERG was performed at presentation, using a custom built system comprising a 61 hexagonal array. ${ }^{4}$ This test facilitates localised assessment of retinal function, within a $90^{\circ}$ retinal field. WF-mfERG showed a global reduction of $\mathrm{Pl}$ amplitude responses in both eyes (Fig 1B). A lower dose of cyclosporin was tried but subsequently discontinued because of significant gastrointestinal symptoms.

Over the next 18 months, tacrolimus, azathioprine, and mycophenolate were all prescribed separately in conjunction with a maintenance dose of $5 \mathrm{mg}$ of prednisolone. Tacrolimus $1 \mathrm{mg}$ twice daily was discontinued after 2 weeks because of intolerable side effects. Treatment with azathioprine $50 \mathrm{mg}$ three times daily continued for 7 months with no improvement in vision. Mycophenolate 1 mg twice daily was stopped at the patient's request after a year, owing to progressive deterioration of vision and a general feeling of malaise. In addition, prednisolone was tailed
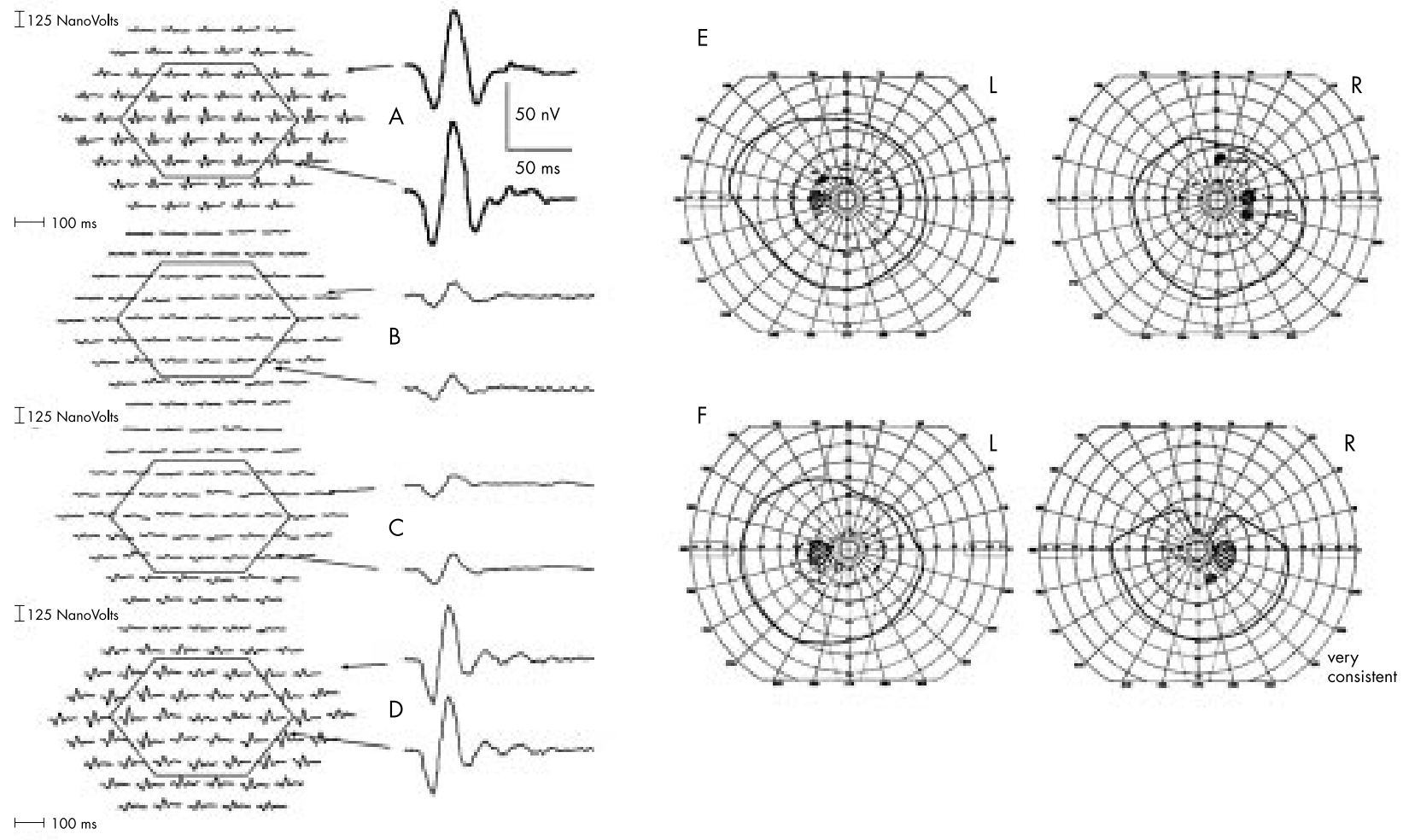

Figure 1 Multifocal electroretinogram (mfERG) of the patient's right eye compared to a normal response. (A) Shows a normal mfERG; the central and peripheral responses are grouped and averaged. The normal range of the central response is $74-122 \mathrm{nV}$ and the normal range of the peripheral response is 61-108 nV. The normal range for mfERG implicit times is $32-42 \mathrm{~ms}$. The ranges are the $5 \%$ and $95 \%$ confidence limits derived from 50 age- matched controls. (B) Shows the mFERG of the patient's right eye performed in 1999 at presentation to the regional uveitis clinic. The average central response is $30 \mathrm{nV}$ and the average peripheral response is $31 \mathrm{nV}$. (C) Shows the mfERG of the right eye performed 1 year later. The average central response is reduced to $21 \mathrm{nV}$ and the average peripheral response is $30 \mathrm{nV}$. The implicit time is delayed by 12-54 ms. (D) Shows the mfERG of the patient's right eye performed 1 year later, 6 months after starting the antioxidant preparation. The average central response shows a marked improvement to $95 \mathrm{nV}$ and the average peripheral has improved to $83 \mathrm{nV}$. The implicit time delay has also improved by $6 \mathrm{~ms}$ to $48 \mathrm{~ms}$. (E) Goldmann perimetry findings before commencing antioxidant treatment. (F) Goldmann perimetry findings 5 months after commencing antioxidant treatment. 
Table 1 List of ingredients in antioxidant preparation. The amount per serving was specified only for those three ingredients listed

\begin{tabular}{|c|c|c|}
\hline Ingredient & Amount per serving & $\begin{array}{l}\text { Percentage of } \\
\text { recommended daily } \\
\text { intake }\end{array}$ \\
\hline \multicolumn{3}{|l|}{ Astaxanthin } \\
\hline \multicolumn{3}{|l|}{ Grape seed extract } \\
\hline \multicolumn{3}{|c|}{ Decaffeinated green tea extract } \\
\hline \multicolumn{3}{|c|}{ Tumeric extract } \\
\hline \multicolumn{3}{|c|}{ Rosemary officinalis extract } \\
\hline \multicolumn{3}{|c|}{ Alpha lipoic acid } \\
\hline \multicolumn{3}{|l|}{ Ellagic acid } \\
\hline \multicolumn{3}{|l|}{ Resveratrol } \\
\hline \multicolumn{3}{|l|}{ Bioflavonoid complex } \\
\hline Carotenoid complex & $9500 \mathrm{IU}$ & $190 \%$ \\
\hline \multicolumn{3}{|l|}{ Co-enzyme Q-10 } \\
\hline \multicolumn{3}{|l|}{ N-acetyl cysteine } \\
\hline Esterified vitamin C & $82 \mathrm{mg}$ & $137 \%$ \\
\hline Vitamin E & $14 \mathrm{IU}$ & $47 \%$ \\
\hline \multicolumn{3}{|l|}{ Glutathione } \\
\hline \multicolumn{3}{|l|}{ Quercitin } \\
\hline \multicolumn{3}{|l|}{ White pine bark extract } \\
\hline \multicolumn{3}{|l|}{ Taurine } \\
\hline \multicolumn{3}{|l|}{ Inositol } \\
\hline \multicolumn{3}{|l|}{ Potassium sulphate } \\
\hline \multicolumn{3}{|l|}{ Selenium } \\
\hline \multicolumn{3}{|l|}{ Selenomethione } \\
\hline \multicolumn{3}{|l|}{ Copper } \\
\hline Zinc monomethionine & & \\
\hline
\end{tabular}

off and stopped after 20 months of steroid treatment. The visual acuity at this stage was $6 / 36, \mathrm{~N} 14$ and 6/12, N14, and the patient was taking no conventional medication. The amplitude of the central and peripheral WFmfERG responses recorded a year after presentation had deteriorated further (Fig IC).

Three months after discontinuing all conventional treatment, the patient began to self medicate with an antioxidant preparation, the contents of which included white and maritime pine bark, grape seed extract, $\beta$ carotene, and vitamins $\mathrm{C}$ and $\mathrm{E}$ (Table 1 ). After 6 months, Snellen acuity had improved to $6 / 15$ $\mathrm{N} 10$ in the right eye and 6/9, N8 in the left. In addition, the amplitude of the central WFmfERG responses had improved from $21 \mathrm{nV}$ to $95 \mathrm{nV}$ in the right eye and from $35 \mathrm{nV}$ to 167 $\mathrm{nV}$ in the left eye (normal range 74-122 nV). The amplitude and implicit time of the average peripheral WF-mfERG responses had also improved in both eyes (Fig ID).

She continued on the antioxidant regimen and 6 months later, the visual acuity and retinal function in both eyes, recorded with the WF-mfERG, had remained stable.

\section{Comment}

WF-mfERG investigations showed a marked improvement in visual function of both eyes after commencing the antioxidant preparation. This observation mirrored the recovery of Snellen acuity but did not correlate with Goldmann perimetry findings (Fig lE and F).

Antioxidants are thought to scavenge free radicals produced in the retina following light absorption, and thus prevent cellular damage that they may produce. ${ }^{67}$ The pathophysiology of BSCR is unclear; therefore the role of antioxidants in reversing the damage caused by BSCR is purely speculative.

In this case it is unclear whether the improvement in visual function, recorded with WF-mfERG was spontaneous, whether it was as a late result of previous conventional treatment, or whether it was secondary to the commencement of a complex non-prescribed antioxidant preparation. The role of antioxidant treatment in BSCR needs further appraisal, perhaps using the HLA-A29 transgenic mouse, which has been shown to spontaneously develop a retinopathy that is histologically very similar to that found in BSCR. $^{8}$

F M Dolan

Ophthalmology Department, Tennent Institute of phthalmology, Gartnavel General Hospital, Grea Western Road, Glasgow G12 OYN,UK

M Gavin

Regional Uveitis Service

S Parks, D Keating

Electrodiagnostic Uni

Correspondence to: Dr Stuart Parks, Electrodiagnostic Imaging Unit, Gartnavel General Hospital, 1053 Great Western Road, Glasgow G12 OYN, UK; s.w.parks@clinmed.gla.ac.uk

Accepted for publication28 October 2002

\section{References}

1 Ryan SJ, Maumenee AE. Birdshot retinochoroidopathy. Am J Ophthalmol 1980;89:31-45.

2 Priem HA, Oosterhuis JA. Birdshot chorioretinopathy: clinical characteristics and evolution. Br J Ophthalmol 1988;72:646-59.

retinochorioretinopathy and HLA-A29+ and HLA-A29 idiopathic retinal vasculitis: comparative study of 56 cases. Can J Ophthalmol 1991;26:361-6.

4 Parks S, Keating D, Evans AL. Wide field functional imaging of the retina. IEEE Medical Applications of Signal Processing 1999;99/107:9/1-9/6

5 Sutter EE, Tran D. The field topography of ERG component in man-1. The photopic luminance response. Vis Res 1992;32:433-46.

6 AREDS. A randomised, placebo-controlled clinical trial of high-dose supplementation with Vitamins $C$ and $E$, beta-carotene, and zinc for age-related macular degeneration and vision loss. AREDS Report No 8. Arch Ophthalmol 2001;119:1417-36.
3 Bloch-Michel E, Frau E. Birdshot
7 Jacques PF, Chylack LT Jr, Hankinson SE, et al. Long-term nutrient intake and early age-related nuclear lens opacities. Arch Ophthalmol 2001;119:1009-19.

8 Szpak Y, Vieville J-C, Tabary T, et al. Spontaneous retinopathy in HLA-A29 transgenic mice. Prot Natl Acad Sci 2001;98:2572-6.

\section{Central retinal venous occlusion with co-existent thrombotic thrombocytopenic purpura and antiphospholipid syndrome}

Central retinal venous occlusion usually occurs in elderly patients with known risk factors such as raised intraocular pressure, arterial hypertension, atherosclerotic disease, or diabetes mellitus. In addition, central retinal venous occlusion infrequently occurs in individuals with hyperviscosity from leukaemia, polycythaemia, Waldenstrom's macroglobulinaemia, sickle cell disease, and periphlebitis. $^{1}$ However, it has also been described in patients with antiphospholipid antibodies ${ }^{2}$ and rarely in patients with thrombotic thrombocytopenic purpura (TTP) (pentad of fever, microangiopathic haemolytic anaemia, thrombocytopenia, neurological abnormalities, and renal impairment). ${ }^{3}$ We describe central retinal venous occlusion in a 26 year old female patient with systemic lupus erythematous (SLE), in whom both TTP and antiphospholipid syndrome (APS) appear to have contributed to the pathogenesis. To our knowledge, co-existence of TTP and APS has not been previously reported in a case of central retinal venous occlusion.

\section{Case report}

The patient presented in 1994, aged 19, with arthralgia and fatigue. Haemoglobin was 3.5 $\mathrm{g} / \mathrm{dl}$ and platelet count $15 \times 10^{9} /$. Investigations revealed SLE (antinuclear antibodies were positive at a titre of $1: 640$ and antidouble stranded DNA antibodies were 1:320)

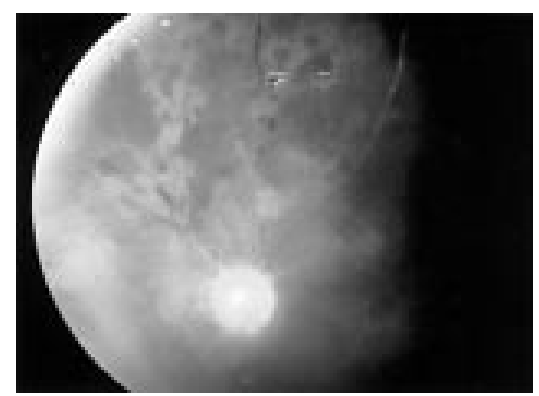

Figure 1 Right central retinal vein occlusion showing pale swollen optic disc and extensive retinal haemorrhages.

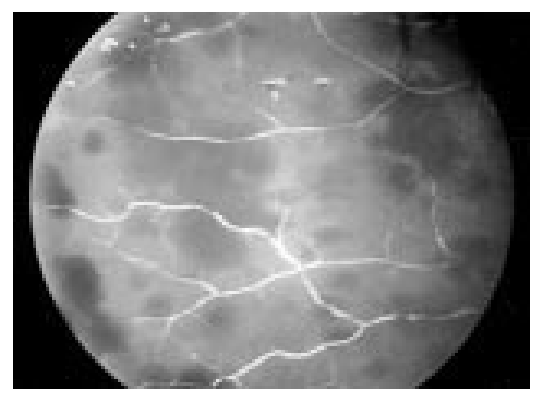

Figure 2 Completely frosted retinal veins indicating severity of vein occlusion. 
with Evans' syndrome (combined autoimmune haemolytic anaemia and immune thrombocytopenia). Tests for APS were not performed. The patient responded to corticosteroids and azathioprine, which were reduced and finally stopped in April 1997.

She remained well until hospitalised in February 2001 with fever of $38^{\circ} \mathrm{C}$, gross haematuria, malaise, poor concentration, and headache. Haemoglobin was $7.5 \mathrm{~g} / \mathrm{dl}$ (Direct Coombs' test negative) and platelet count $1 \times$ $10^{9} / \mathrm{l}$. Serum creatinine was $244 \mu \mathrm{mol} / \mathrm{l}$ and activated partial thromboplastin time was prolonged at 93 seconds. IgG anticardiolipin antibodies were elevated (18 GPL units/ml) and lupus anti-coagulant was detected by a positive kaolin clotting time index and a dilute Russell viper venom test. C3 and C4 complement components were reduced at 6.6 $\mathrm{g} / \mathrm{l}$ (normal, 7.5-17 g/l) and 0.4 g/l (normal, 1.4-5.4 g/l) respectively, indicating activation of the classic complement pathway by immune complexes.

She was treated with intravenous antibiotics, blood transfusion and, for the presumptive diagnosis of immune thrombocytopenia, high dose corticosteroids. Early next morning, she complained of sudden onset loss of vision in the right eye. On ophthalmic examination, her visual acuity was hand movements in the right eye and 6/6 in the left eye. She had a dense right relative afferent pupillary defect and right fundal examination revealed completely frosted retinal veins and a severe haemorrhagic central retinal vein occlusion with diffuse superficial and deep retinal haemorrhages (Figs 1 and 2). As the platelet count remained low at $2 \times 10^{9} / \mathrm{l}$, 3 day course of intravenous immunoglobulins $(400 \mathrm{mg} / \mathrm{kg} /$ day) was commenced. On the third day of hospitalisation, vision in the right eye had not improved and the platelet count remained $<5$ $\times 10^{9} /$ l. Review of daily blood films revealed increased numbers of fragmented red cells (schizocytes) while serum LDH was 2049 units/ (normal $<450$ units/1). A diagnosis of TTP secondary to SLE was made and treatment with 1 litre of cryoprecipitate poor fresh frozen plasma (FFP) twice daily was started. Within 36 hours, the platelet count had risen to $39 \times 10^{9} / 1$ and aspirin and azathioprine were added. After a week's therapy with cryoprecipitate poor FFP, platelet count, serum creatinine, and serum LDH were all within normal range with normal blood film.

Three months later, the right eye had developed rubeosis irides, raised intraocular pressure of $34 \mathrm{~mm} \mathrm{Hg}$, disc new vessels, and early vitreous haemorrhage. Following treatment with topical $\beta$ blockers and multiple sessions of panretinal argon laser photocoagulation, the disc new vessels and rubeosis resolved but visual acuity remained poor at hand movements. Ten months later, the patient is taking prednisolone, azathioprine, and aspirin without evidence of TTP but without recovery of vision in the right eye.

\section{Comment}

In a recent review, anticardiolipin antibodies were detected in eight of 17 patients with SLE and TTP. ${ }^{4}$ Antiphospholipid antibodies, therefore, may contribute to the pathogenesis of some cases of TTP in association with SLE, possibly by causing endothelial damage in the microvasculature. TTP is a rare but recognised association with central retinal venous occlusion $^{3}$ while a high prevalence of anticardiolipin antibodies has been reported in patients with vaso-occlusive retinopathy exempt from conventional risk factors. ${ }^{2}$ However, to our knowledge, this present case of central retinal venous occlusion is unique because of co-existent APS and TTP secondary to SLE. Although aggressive immunosuppressive therapy, aspirin and cryoprecipitate poor FFP led to control of APS and TTP, the severe visual impairment due to central retinal venous occlusion failed to recover.

P T Murphy

Department of Haematology, Royal Shrewsbury Hospital, Shrewsbury, UK

P Rao

Department of Opthalmology

Correspondence to: Dr P T Murphy, Department of Haematology, Beaumont Hospital, Dublin 9, Ireland; philip.murphy@beaumont.ie

Accepted for publication 13 March 2002

\section{References}

1 Hayreh SS, Zimmerman MB, Podhajsky BSN. Incidence of various types of retinal vein occlusion and their recurrence and dermographic characteristics. Am J Opthalmol 1994; 117:429-41.

2 Cobo-Soriano R, Sanchez-Ramon S, Aparicio M, et al. Antiphospholipid antibodies and retinal thrombosis in patients without risk factors: a prospective case-control study. Am J Opthalmol 1999;1 28:725-32.

3 Costa JR, Frause M, Friedman E, et al. Central retinal vein occlusion in a patient with thrombotic thrombocytopenic purpura. Am J Opthalmol 2001:131:669-71.

4 Musio F, Bohen EM, Yuan CM, et al. Review of thrombotic thrombocytopenic purpura in the setting of systemic lupus erythrematosus. Semin Arthritis Rheum 1998;28:1-19.

\section{MAILBOX}

If you have a burning desire to respond to a paper published in the BJO, why not make use of our "rapid response" option?

Log on to our website (www.bjophthalmol.com), find the paper that interests you, and send your response via email by clicking on the "eletters" option in the box at the top right hand corner.

Providing it isn't libellous or obscene, it will be posted within seven days. You can retrieve it by clicking on "read eletters" on our homepage.

The editors will decide as before whether to also publish it in a future paper issue.

\section{Further considerations of retinopathy with renal failure}

We were interested to read the letter by Patel et al reporting the unusual and striking fundus appearance of retinal arteriolar calcification in association with chronic renal failure. ${ }^{1}$ However, we feel that two important conditions have been omitted from the comment, which merit further discussion.

Firstly, Monckeberg's sclerosis, which in its classic form is characterised by "pipe stem" calcific deposition in the medial coat of muscular arteries in middle aged and elderly individuals, ${ }^{2}$ and is described with widespread systemic distribution. ${ }^{34}$ Interestingly though, a juvenile form is seen, particularly in association with chronic renal failure and diabetes. ${ }^{5}$ The pathological mechanism of Monckeberg's sclerosis is uncertain, but is thought to encompass elements both of dystrophic and metastatic calcification. ${ }^{6}$ In the reported case, it would be of interest to know if there was any evidence of vascular calcification elsewhere in this individual, or whether it was localised to the retinal arterioles only.

Secondly, Senior-Loken syndrome (renalretinal syndrome, nephronophthisis associated with retinitis pigmentosa, or retinal aplasia) is also germane to this discussion. ${ }^{7}$ Nephronophthisis is a major cause of progressive medullary cystic renal disease leading to chronic renal failure in adolescents. ${ }^{8}$ It is associated with a variable retinal phenotype, a reflection of both clinical and genetic heterogeneity. When associated with retinitis pigmentosa, there is an absence of the classic bone spicule pigmentation, but optic nerve head pallor and attenuation of the blood vessels is seen. Also, electroretinographic alterations have been reported in nephronophthisis despite normal a normal fundus examination. ${ }^{9}$ In view of the phenotypic overlap seen with the reported case, results of electroretinography would be pertinent to the discussion. We would also advocate a molecular genetic analysis at the known loci associated with Senior-Loken syndrome, which could potentially reveal an interesting new allelic variant.

Finally, while the fundus photograph elegantly demonstrates the stark changes seen in the retinal vasculature; this evidence could be further augmented by the addition of an ultrasound B-scan image demonstrating the pathognomonic echogenic features of intraocular calcification.

M D Mohamed

Vision Research Group, Molecular Medicine Unit, University of Leeds, Leeds, UK

M A McKibbin

Eye Clinic, St James's University Hospital, Beckett Street, Leeds LS9 7TF, UK

Correspondence to: Moin D Mohamed; moinm@hotmail.com

\section{References}

1 Patel DV, Snead MP, Satchi K. Retinal arteriolar calcification in a patient with chronic renal failure. Br J Ophthalmol 2002;86: 1063.

2 Juergens JL. Peripheral vascular diseases. 5th ed. Philadelphia: WB Saunders, 1980:238-40.

3 Lachman AS, Spray TL, Kerwin DM, et al. Medial calcinosis of Monckeberg. A review of the problem and a description of a patient with involvement of peripheral, visceral and coronary arteries. Am J Med 1977;63:615-22.

4 Castillo BV Jr, Torczynski E, Edward DP. Monckeberg's sclerosis in temporal artery biopsy specimens. Br J Ophthalmol 1999;83:1091-2

5 Top C, Cankir Z, Silit E, et al. Monckeberg's sclerosis: an unusual presentation. Angiology 2002;53:483-6.

6 Byts' IuV, Holdobina OV, Dosenko VI, et al. The current concepts of the pathogenesis of Monckeberg-type arteriosclerosis. Fiziol Zh 2000;46:64-72.

7 Online Mendelian Inheritance in Man, OMIM (TM). Baltimore, MD: Johns Hopkins University, MIM Number: 266900 : 6/10/2002; http://www.ncbi.nlm.nih.gov/ omim/

8 Gusmano R, Ghiggeri GM, Caridi G Nephronophthisis-medullary cystic disease: clinical and genetic aspects. J Nephrol 1998;11:224-8

9 Orssaud C, Kleinknecht C, Habib R, et al. Hereditary chorioretinal degeneration and nephronophthisis. The role of Senior-Loken syndrome. Ophtalmologie 1989;3:270-2. 


\section{Comments on myopia in secondary school students in Tanzania}

I refer to the interesting article ${ }^{1}$ by Wedner $e t$ al published recently in the BJO. The author have concluded, without enough justification, that "an eye screening programme for significant refractive errors is indicated in this population." I believe more data are required for such a conclusion.

Wedner et al could have reported the true positive predictive rate for the detection of myopia using the stated referral criterion of "worse than 6/12" on the Snellen visual acuity chart: $141 / 174$ or $81 \%(95 \%$ CI: 74 to 86$)$. However, they have referred to the prevalence of "significant" myopia being 141/2511 or 5.6\% In epidemiological convention it is incorrect to apply this denominator and report this prevalence rate because the reference standard for the determination of refractive errorsthat is, refraction, has not been performed in the majority (2337) of the 2511 students. The positive predictive value of a screening test is influenced by the prevalence of the condition to be screened (that is, myopia). Nevertheless, without experimental data on the false negative subjects, the actual prevalence cannot be determined. Therefore, true prevalence of myopia cannot be determined given the study design. In a study conducted in Singapore, for example, each one of the 1003 children in the sample has been subjected to refraction as well as the screening test (visual acuity). With a cut-off criterion of $\log$ MAR 0.30 , the positive predictive value was as high as $95.4 \%(95 \% \mathrm{CI}$ 92.6 to 97.2 ), but the actual prevalence of myopia was only $33.8 \%$ (95\%CI: 30.9 to 36.8). ${ }^{2}$ At least one of the studies cited ${ }^{3}$ by Wedner et al has employed refraction in the entire study sample and this may very well be a reason for the previously reported relatively higher myopia prevalence rates (in the true sense of the word).

In the discussion section of the paper, ${ }^{1}$ it was assumed without justification, that only the "lower degrees of hyperopia" would be undetected by their visual acuity test. In fact, some proportion of all types of refractive errors could escape the best compromise threshold on visual acuity testing. ${ }^{2}$ If a subject could pass the visual acuity criterion on one occasion, one should not assume that he is no myopic or even, to have such low myopia that he is functionally normal.

L Tong

11, 3rd Hospital Avenue, Singapore 168751 lovistong@hotmail.com

\section{References}

1 Wedner SH, Ross DA, Todd J, et al. Myopia in secondary school students in Mwanza City, Tanzania: the need for a national screening programme. BrJ Ophthalmol 2002;86:1200-6.

2 Tong L, Saw SM, Tan D, et al. Sensitivity and specificity of visual acuity screening for refractive errors in school children. Optom Vis Sci 2002:79:650-7.

3 Lin LL, Shih YF, Tsai CB. Epidemiologic study of ocular refraction among schoolchildren in Taiwan in 1995. Optom Vis Sci 1999;76:275-81.

4 Spicer PJ, Ansell FJ. Comparison of visual acuity tests and viewing condition interactions. Aerosp Med 1973;44:1290-4.

\section{Left handed non-dominant hand phacoemulsification}

We appreciate the commendable work by Kageyama et al, which was published in the
BJO. ${ }^{1}$ We have also studied the results of left handed non-dominant hand phacoemulsification prospectively, performed in left eyes of 29 patients with an immature senile cataract and against the rule astigmatism. Phacoemulsification was performed by an experienced surgeon (RBV) under peribulbar anaesthesia. The surgeon sat at the head end of the patient while performing these operations (on left eyes). In all the cases, a $3.2 \mathrm{~mm}$ clear corneal temporal incision was made with a diamond knife held in the left hand of the surgeon. Following a continuous curvilinear capsulorhexis and hydroprocedures a phaco chop nucleotomy technique was done using Storz Protégé phaco machine. The chopper was held in the right hand of the surgeon and inserted from the 12 o'clock side port and the phaco probe was held in the left hand of the surgeon and introduced from the main incision on the temporal side. This was followed by automated irrigation aspiration and implantation of an Acrysof foldable intraocular lens (Alcon MA 60 BA) in the capsular bag.

In our study of 29 patients the mean age of the patients was slightly younger, 63.50 (SD 9.61 ) years (range $43-80$ years), than patients of Kageyama et al. Out of 29 eyes, nucleus hardness was grade 3 or more in 17 eyes in our series. It would be worthwhile to know the nuclear hardness in the series reported by Kageyama et al as the manoeuvres in hard cataract may be more difficult to perform with the non-dominant hand.

The mean ultrasound power used in our cases was $25.7 \%(9.5 \%)$ and the mean effective phacoemulsification time was 18 (11) seconds. No posterior capsular tear or vitreous loss was present in our cases and this could be attributed to the fact that an experienced surgeon performed the surgery. However, were there any anterior capsular tears noted by Kageyama et al, which occurred in two eyes in our series during the chopping procedure? Nevertheless, none of these cases had a posterior extension of the tear with vitreous loss. Twenty seven eyes (93.1\%) achieved a best corrected visual acuity of $20 / 20$ at 4 weeks after the surgery, while two eyes had a best corrected visual acuity of 20/40 because of the presence of age related macular degeneration. It would be also worthwhile to know the amount of astigmatism preoperatively and postoperatively reported by Kageyama et al, as one of the advantages of a temporal incision phaco is less surgically induced astigmatism. ${ }^{2}$ The mean preoperative keratometric ATR astigmatism was 0.54 (0.44) D (range 0.25 to $2 \mathrm{D}$ ) and the mean postoperative ATR astigmatism was 0.25 (0.64) D (range -0.75 to $1.75 \mathrm{D}$ ) (Wilcoxon signed rank test, $p=0.0267$ ) in our series. We had a similar mean endothelial loss of $6.02 \%$ at the end of 12 weeks.

Clear corneal non-dominant hand phacoemulsification is indeed a safe and efficacious method. This obviates the need for a surgeon to change position between cases. In addition, the dominant hand is utilised for chopping, which makes the chopper the most active instrument, while the non-dominant hand holds the ultrasound hand piece as a passive instrument in the centre of the capsular bag. This helps to reduce the use of ultrasound energy for nuclear management, as the chopper is the primary instrument used for mechanical disintegration of the nucleus.
R B Vajpayee, P Moulick, N Sharma, R Tandon

Dr Rajendra Prasad Centre for Ophthalmic Sciences, All India Institute of Medical Sciences, New Delhi, India

Correspondence to: Rasik B Vajpayee; rasikvajpayee@rediffmail.com

\section{References}

1 Kageyama T, Yaguchi S, Metori Y, et al. Visual results and complications of temporal incision phacoemulsification performed with the non-dominant left hand by junior ophthalmologists. Br J Ophthalmol 2002:86:1222-4.

2 Kohnen T, Dick B, Jacobi KW. Comparison of the induced astigmatism after temporal clear corneal tunnel incision of different sizes. J Cataract Refract Surg 1995;21:417-24.

\section{Left handed non-dominant hand} phacoemulsification

This interesting paper ${ }^{1}$ seems to lack one essential attribute-common sense. To operate "from the top" with the non-dominant hand in the temporal position surely does not equate to a comfortable operating position for the surgeon. A better and much simpler solution, to avoid moving equipment around between cases, is to book only right eyes on one operating list, and left eyes on another.

We have to be careful not to trivialise an operation that is becoming faster and faster to perform as ultrasound and lens technology improves. Perhaps non-dominant handed surgeons could be replaced by dominant-handed technicians. I know which hand I would rather my surgeon use.

T R G Poole

Moorfields Eye Hospital, City Road, London ECIV 2PD, UK; trgp@fish.co.uk

\section{Reference}

1 Kageyama T, Yaguchi S, Metori Y, et al.

Visual results and complications of temporal incision phacoemulsification performed with the non-dominant left hand by junior ophthalmologists. Br J Ophthalmol

2002;86:1222-4.

\section{NOTICES}

\section{Monitoring cataract surgical outcomes}

The latest issue of Community Eye Health (No 44) discusses the monitoring of cataract surgical outcomes in the Third World. For further information please contact: Journal of Community Eye Health, International Centre for Eye Health, Institute of Ophthalmology, 1 1-43 Bath Street, London ECIV 9EL, UK (tel: +44 (0)20 7608 6910; fax: +44 (0)20 7250 3207; email: eyeresource@ucl.ac.uk; website: www.jceh.co.uk). Annual subscription (4 issues) UK£25/US\$40. Free to workers in developing countries.

\section{International Centre for Eye Health}

The International Centre for Eye Health has published a new edition of the Standard List of Medicines, Equipment, Instruments and Optical Supplies (2001) for eye care services in developing countries. It is compiled by the Task Force of the International Agency for the Prevention of Blindness. Further details: Sue Stevens, International Centre for Eye Health, 11-43 Bath Street, London ECIV 9EL, UK 
(tel: $+44 \quad(0) 207608$ 6910; email: eyeresource@ucl.ac.uk).

\section{Second Sight}

Second Sight, a UK based charity whose aims are to eliminate the backlog of cataract blind in India by the year 2020 and to establish strong links between Indian and British ophthalmologists, is regularly sending volunteer surgeons to India. Details can be found at the charity website (www.secondsight.org.uk) or by contacting Dr Lucy Mathen (lucymathen@yahoo.com).

\section{SPecific Eye ConditionS (SPECS)}

SPecific Eye Conditions (SPECS) is a not for profit organisation which acts as an umbrella organisation for support groups of any conditions or syndrome with an integral eye disorder. SPECS represents over fifty differen organisations related to eye disorders ranging from conditions that are relatively common to very rare syndromes. We also include groups who offer support of a more general nature to visually impaired and blind people. Suppor groups meet regularly in the Boardroom at Moorfields Eye Hospital to offer support to each other, share experiences, and explore new ways of working together. The website www.eyeconditions.org.uk acts as a porta giving direct access to support groups' own sites. The SPECS web page is a valuable resource for professionals and may also be of interest to people with a visual impairment or who are blind. For further details about SPECS contact: Kay Parkinson, SPECS Devel opment Officer (tel: +44 (0)1803 524238; email: k@eyeconditions.org.uk; web site: www.eyeconditions.org.uk)

\section{The British Retinitis Pigmentosa} Society

The British Retinitis Pigmentosa Society (BRPS) was formed in 1975 to bring together people with retinitis pigmentosa and their families. The principle aims of BRPS are to raise funds to support the programme of medical research into an eventual cure for this hereditary disease, and through the BRPS welfare service, help members and their families cope with the everyday concerns caused by retinitis pigmentosa. Part of the welfare service is the telephone help line $(+44$ (0) 1280860363 ), which is a useful resource for any queries or worries relating to the problems retinitis pigmentosa can bring. This service is especially valuable for those recently diagnosed with retinitis pigmentosa, and al calls are taken in the strictest confidence. Many people with retinitis pigmentosa have found the Society helpful, providing encouragement and support through the help line, the welfare network, and the BRPS branches throughout the UK. (tel: +44 (0)1280 821 334; email: lynda@brps.demon.co.uk; web site: www.brps.demon.co.uk

\section{Surgical Eye Expeditions International}

Volunteer ophthalmologists in active surgical practice are needed to participate in short term, sight restoring eye surgery clinics around the world. Contact: Harry S Brown, Surgical Eye Expeditions International, 27 East De La Guerra, C-2, Santa Barbara, CA 93101-9858, USA (tel: +805 963 3303; fax: +805 965 3564; email: hsbrown.md@cox.net or seeintl@seeintl.org; web site:www. seeintl. org).

\section{Retinal Detachment Course}

The XXXII Retinal Detachment Course with International Faculty and Case Presentations will be held 5-6 June 2003, in Beijing, China. The Congress language is English with simultaneous translation in Chinese. Further details: Scientific programme: Prof Ingrid Kreissig, University of Tuebingen, Schleichstr. 12, Breuningerbau, 72076 Tuebingen, Germany (tel: $+49 \quad 7071 \quad 295209 ; \quad$ email: ingrid.kreissig@med.uni-tuebingen.de).

Local organisation: Ningli Wang, Liang $\mathrm{Xu}$, Wu Liu. Congress office: Wu Liu, Beijing Tong Ren Eye Center, Beijing 100730, China (email: wuliubj@yahoo.com).

\section{Detachment Course with international faculty on: Retinal and Vitreous Surgery with Case Presentations preceding the Annual Meeting of Iranian Society of Ophthalmology}

The detachment course with international faculty on: Retinal and Vitreous Surgery with Case Presentations preceding Annual Meeting of Iranian Society of Ophthalmology will be held on 29-30 November 2003 and 1-4 December 2003 respectively, at the Razi Conference Center, Hemmat Hyw, Tehran, Iran. Further details: Scientific programme: Prof Ingrid Kreissig, University of Tuebingen, Schleichstr. 12, Breuningerbau, 72076 Tuebingen, Germany (tel: +49 7071 295209; email:ingrid.kreissig@med.uni-tuebingen.de.) Local organisation: Dr Arman Masheyekhi, Dr Siamak Moradian, Dept of Ophthalmology, Labbanfinejad Medical Center, Pasdaran Ave, Boostan 9, Tehran, 16666, Iran (fax: +98 21254 9039; email: labbafi@hotmail.com). 